Estudios sobre armas antiguas, arte militar y vida cultural en oriente y occidente

XXXVIII (2018), pp. 99-124

ISSN: 0436-029X

https://doi.org/10.3989/gladius.2018.07

\title{
LA ARTILLERÍA EN EL REINO DE CASTILLA Y LEÓN DURANTE EL SIGLO XV
}

THE ARTILLERY IN THE KINGDOM OF CASTILE DURING THE XV ${ }^{\text {TH }}$ CENTURY

POR

\author{
José Javier de Castro Fernández y Javier Mateo de Castro**
}

\section{RESUMEN - ABSTRACT}

La artillería del reinado de Juan II y Enrique IV ha sido tradicionalmente dejada de lado frente al gran desarrollo acontecido en este ámbito durante el gobierno de los Reyes Católicos. Sin embargo, el análisis de las políticas puestas en marcha por el padre y el hermanastro de Isabel en el trono castellano muestra un gran número de avances en la fabricación y uso de las armas artilleras, hecho que permite comprender los logros posteriores. Además, la historiografía tradicional no abordó el papel jugado por los poderosos nobles castellanos del siglo XV, emitiendo por ello un juicio sesgado sobre la artillería de aquel momento.

The artillery of Juan II and Enrique IV's reigns has been traditionally left aside facing the great development caused in this field during the Catholic Kings' rule. Nevertheless, the analysis of the policies put into action by Isabel's father and half-brother shows the advances in the manufacturing and use of the artillery arms, which allows us to understand the past achievements. Moreover, the traditional historiography did not address the role played by the powerful Castilian noblemen during the 15 th century, due to this a biased judgement of the artillery from that period was passed.

\section{Palabras Clave - Keywords}

Artillería; Castilla; Juan II; Enrique IV.

Artillery; Castile; Juan II; Enrique IV.

\section{Cómo CitAR eSte ARTículo / CitATion}

De Castro Fernández, J. J. y Mateo de Castro, J. (2018): «La artillería en el Reino de Castilla y León durante el siglo XV». Gladius, XXXVIII: 99-124. https://doi.org/10.3989/gladius.2018.07

\section{INTRODUCCIÓN}

El estudio de la artillería de la Corona de Castilla y León desde principios del siglo XV ${ }^{2}$ hasta el inicio de la guerra de Granada es un ámbito de la historia militar poco estudiado y en

* Asociación Española de Amigos de los Castillos, jjdecastro@yahoo.es / ORCID iD: http://orcid.org/0000-00022140-2215.

** Universidad Complutense de Madrid, jmateodecastro@gmail.com / ORCID iD: http://orcid.org/0000-0002-18119953.

2 La primera representación del Alcázar de Segovia se da en una tabla de finales del siglo XV. (De Castro, 2004: 320). 
el que apenas se ha avanzado desde lo publicado por investigadores del siglo XIX como Salas, Carrasco o Arántegui ${ }^{1}$. Los avances del siglo XX tampoco supusieron un avance reseñable en este ámbito, como se puede comprobar en la obra Historia de la Artillería Española (Vigón, 1947), lo cual evidencia la necesidad de acometer este estudio. Por el contrario, la historiografía militar del reinado de los Reyes Católicos ${ }^{2}$ y la Guerra de las Comunidades de Castilla ha sido más ampliamente tratada, publicándose recientemente varios estudios que han puesto de relieve la importancia de la artillería de avancarga fundida en bronce en los últimos años del siglo XV y primeros del siglo XVI (De Castro y Mateo, 2016).

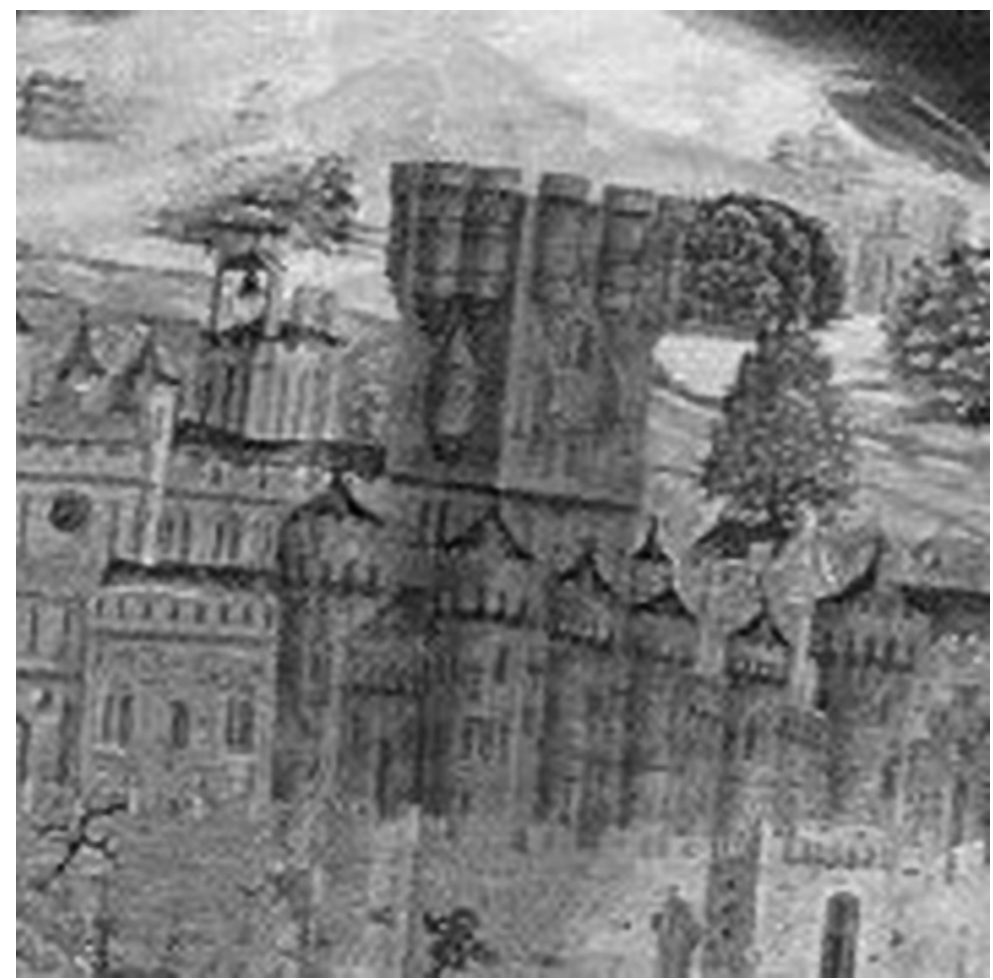

Figura 1. Primera representación conocida del Alcázar de Segovia. (Nota 3) Retablo de la iglesia de San Millán en Los Balbases.

Por lo anteriormente dicho, en este estudio vamos a tratar de evidenciar el alto grado de desarrollo alcanzado por la artillería castellana durante el siglo XV, demostrando que se encontraba al mismo nivel, si no superior, al de otros reinos peninsulares, frente a lo afirmado por los historiadores del siglo XIX. Desarrollo no solo alcanzado por la Corona, sino secundado por una nobleza que desde fechas muy tempranas incorpora las armas de fuego al arsenal de sus castillos señoriales, como nos demuestran los inventarios de artillería estudiados del siglo XV.

1 Deben destacarse publicaciones como Memorial histórico de la artillería española (Salas, 1831); «Apuntes para la historia de la fundición de artillería de bronce en España» (Carrasco, 1887); «Apuntes de la historia de la fabricación de artillería y proyectiles de hierro» (Carrasco, 1889) y Apuntes históricos sobre la artillería española en los siglos XIVy XV (Arántegui, 1887).

2 Son de destacar las obras colectivas La artillería de los Reyes Católicos (Cobos, 2004) y Artillería y Fortificaciones en la Corona de Castilla durante el reinado de Isabel la Católica (1474-1504) (Valdés, 2004). 
A principios del reinado de Juan II, la Corona no sólo había alcanzado un gran perfeccionamiento en la artillería de forja de hierro, sino también en la fundición de cañones de metal -bronce, fuslera o azofar, sinónimos indistintamente utilizados en documentación castellana de la época-, como prueban la fundición de Sevilla de 1408 o las realizadas durante la contienda de 1429 contra los reinos de Aragón y Navarra.

En este periodo se va a producir un hecho único en los reinos peninsulares: el primer intento por parte de la Corona castellana de crear una fundición totalmente autárquica de bronce. Será a finales del reinado de Juan II cuando se establezca, al pie de sendas minas de cobre y estaño en la Sierra de la Demanda, una factoría. Este hecho evitará a la Corona depender de la importación del cobre foráneo, lográndose controlar por primera vez todo el proceso de fundición de las armas de bronce.

En lo relativo a los responsables del proceso de fundición de armas artilleras de bronce en el territorio castellano, debe mencionarse que estos eran siempre fundidores especializados, un personal cualificado que conocía perfectamente el porcentaje de cobre y estaño para la obtención del bronce idóneo para la fabricación de cañones. Debemos desterrar por inexacta la afirmación que indica que, al estar las fundiciones en manos de campaneros, el porcentaje de estaño era muy elevado y las piezas obtenidas resultaban muy frágiles. Como veremos, la labor de los campaneros se limitaba a ser mano de obra cualificada al servicio de los fundidores y el porcentaje empleado de cobre y estaño apenas se modificó durante todo el siglo XV, siendo la misma fórmula - con escasas variaciones - que la utilizada en época moderna.

De forma simultánea al desarrollo de la fundición, se va formando el cuerpo de artillería con el nombramiento por parte de la Corona de un responsable específico de todo lo relativo a la artillería con el título de maestro mayor, encargado tanto de la dirección militar y efectiva del cuerpo como también de las labores de fundidor. Debe recordarse que, en aquel momento, el termino artillería servía tanto para aludir a las nuevas armas de fuego y las antiguas de torsión: «artillerías de engenios e lombardas» (Pérez de Guzmán, 1779, XVI: 299).

Respecto del número de modelos de piezas, estos van aumentando durante el periodo tratado, cubriéndose todas las posibilidades: desde la gran lombarda hasta la espingarda. En el ámbito de la técnica, los tiros se crean indistintamente en hierro forjado o en bronce, contando en ambos casos la pieza con caña y recámara. Esta hibridación de técnicas implicará que lleguen a crearse piezas compuestas por ambos materiales: la caña de hierro y la recámara de bronce o viceversa.

Una de las novedades más importantes que se dan en el periodo es el uso del cartucho de papel, inédito hasta ahora, y que queda constatado documentalmente. Asimismo, destaca la creación de la artillería para batalla campal, con piezas específicas como el desbarabatallas, descrito como un tiro de fuslera que son varios cañones juntos en uno.

Por su parte, la necesaria actualización de las fortalezas ante las nuevas armas artilleras se realiza principalmente mediante la denominada barrera artillera, consistente en una muralla perimetral que rodea el castillo y en la que se emplazan cañones conocidos como culebrinas de barrera.

\section{SITUACIÓN DE LA ARTILLERÍA EN EL REINADO DE JUAN II}

Las Cortes castellanas de 1406, las últimas del rey Enrique III, proponen para la guerra contra Granada dotar al cuerpo de artillería con «seis gruesas lombardas, cien tiros de pólvora no tan grandes, dos ingenios y doce trabucos» (Pérez de Guzmán, 1779, X: 4). Esta cita demuestra la gran importancia que tiene el arma de artillería ya a comienzos del siglo XV en 


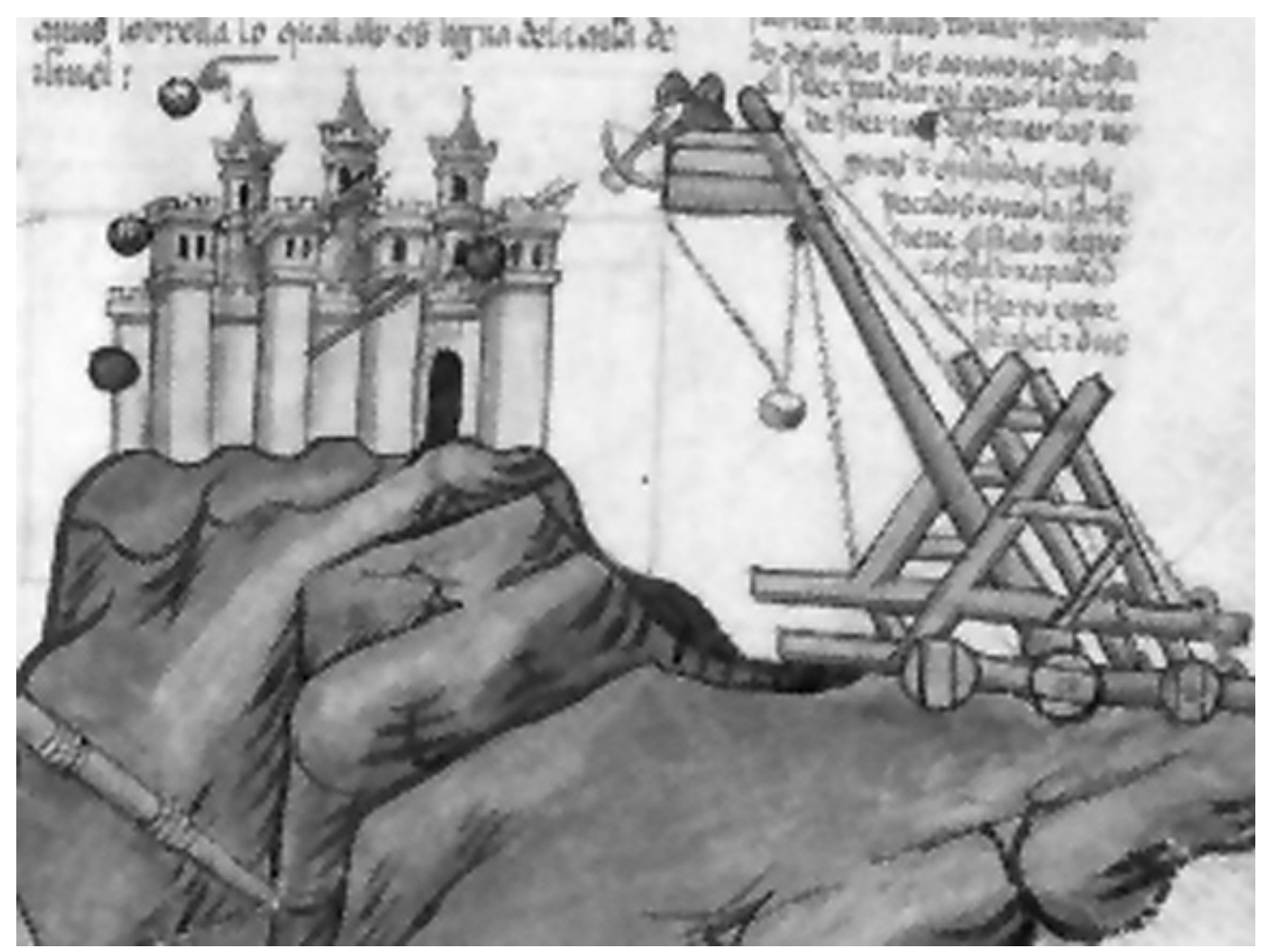

Figura 2. Bastida contra un castillo. Biblia de Alba.

el reino de Castilla y León. El hecho de que se proponga un parque artillero de tal magnitud indica que, al menos desde el reinado de Enrique III, ya se había alcanzado un gran nivel de desarrollo tanto en número de piezas como en el nivel organizativo de las mismas. Sabemos que dirigiendo el uso de las mismas estaba Bernal Pérez «maestro de mis gombardas» y que Juan Sánchez de Segura era el «maestro de hacer truenos». También destacaba el «ingeniero» Diego Alfonso quien trabaja para el concejo de Murcia al «fazer algunas gonbardas e poívora» (Torres, 1980: 115), posteriormente está en Baza y con el infante Fernando de Antequera.

En la campaña de 1407 contra Granada se emplean un total de tres grandes lombardas de hierro - llamadas Grande, Gijón y la Banda-, dos lombardas de fuslera y dieciséis truenos (De Mata, 1982: 144-148). La siguiente campaña de 1410, comandada por el infante Fernando y que finaliza con la conquista ese mismo año de Antequera, nos muestra de una manera muy nítida el potencial de la Corona castellana. A la artillería de 1407 depositada en el alcázar de Jerez de los Caballeros (González, 2013) el Infante incorpora una nueva remesa artillera formada por dos lombardas de bronce y doce truenos, configurando uno de los mayores trenes artilleros de la Corona castellana.

Los preparativos para la constitución de este gran tren artillero se centralizan en Sevilla, donde se construye una casa de artillería para que Jacome Rendeler de Francoforte, «maestro de gombardas» (Vilaplana, 1974), ayudado por los maestros Johan y Miguel, maestros de hacer gombardas, y el campanero Antón López, fundan en metal un total de dos lombardas y doce truenos, y fabriquen fuego griego de alquitrán entre 1408 y 1409. Respecto de los proyectiles, las piezas fundidas disparaban proyectiles de piedra.

Para la fundición se compra cobre proveniente de Romania y Flandes y junto con el estaño adquirido en Sevilla se obtiene un bronce con la siguiente proporción: 89,47 de cobre y 
10,53 de estaño, muy similar a la que alcanzará las fundiciones reales de los Reyes Católicos a finales del siglo XV. Como podemos observar, la proporción para la obtención de bronce es la que estipulaban los maestros fundidores europeos (López, 2011) y la Corona cuenta con fundidores especializados y los campaneros quedan relegados a labores de apoyo, como se comprueba por el salario abonado a cada uno; mientras el fundidor cobra cuarenta maravedís al día, el campanero sólo quince, pues sueldo, responsabilidad y conocimiento van parejos.

En la casa de artillería de Sevilla se fundieron dos lombardas, llamadas Santa Cruz y Santa María de Guadalupe, si bien se efectuaron tres fundiciones al fallar una de ellas porque se «helo el cobre» (Vilaplana, 1974). Para la fundición se construyó un molde y el ánima con «cera e sevo e barro que fue menester para facer la forma» (Vilaplana, 1974). Además se emplearon otros materiales, como latón, hierro, barras, cuñas, cabríos, carbón, leña y barro, así como herramientas, sogas, espuertas, jornales de maestros herreros y carpinteros, peones y bestias. Un detalle curioso es que el aspecto exterior de las lombardas de hierro y bronce era muy similar, ya que también a estas últimas se les incorporaban como refuerzo los cinchos o duelas, referidas en la documentación como cercos para cuya fabricación se compra cera, leña y carbón. La existencia de cera nos vuelve a remitir al empleo de moldes y por tanto las duelas también serían de metal.

El fundidor sería Jacomo, Jacome o Jacomin, citado en la Crónica de Juan II, que actúa como lombardero y responsable del tren artillero durante el asedio de Antequera y a quien el cronista atribuye la nacionalidad alemana. Su buena labor hace que la Corona le conceda una ayuda para la compra de unas casas en Sevilla, en donde todavía residía en 1429 en la colación de la Magdalena (Gestoso, 1899: 368).

El desarrollo del arma artillera continúa imparable y en la guerra de 1429 contra Aragón y Navarra, la Corona de Castilla dispone de un gran número de maestros fundidores en metal para la construcción de lombardas y truenos. El material que se funde y fabrica para la contienda es ejecutado por maestre Jacome Rendeler, quien funde cuatro lombardas de «cobre» ${ }^{3}$, los cántabros Alonso Martínez Ximón, Pedro Gutiérrez Ximón y Juan Ximón ${ }^{4}$ con tres lombardas, Martín Sánchez de Vedía ${ }^{5}$, Juan Hano con dos medias gombardas, Nicolás Martínez con cien truenos, Andrés Martínez con cien truenos y Manuel de Peñafiel con cincuenta truenos. Como vemos, el parque artillero que moviliza la Corona de Castilla es impresionante. Este armamento fue fundido y fabricado en Soria, Moya, Vitoria y Peñafiel. Además se incorporó el parque existente en Valladolid, consistente en dos lombardas y once truenos, y al frente del cual se encontraba el artillero real Nicolás Ortiz ${ }^{6}$. Estas piezas de artillería empleadas en el ejército castellano tenían diversos calibres. Así, las lombardas iban desde los cinco a los cuatro y tres quintales, llegando las de menor tamaño a solo medio quintal. Por su parte, los truenos eran de tres calibres disparando proyectiles de ocho, seis y cuatro libras.

Durante el reinado de Juan II los principales tipos de piezas de artillería eran las lombardas y los truenos, piezas construidas indistintamente en hierro o bronce que disparaban pelotas de piedra. El arma constaba de dos partes: la caña y el servidor. En el reino de Castilla el término cañón se usa para denominar la caña o trompa, palabra que evoluciona a principios de siglo para definir la pieza de artillería de un solo bloque, una vez que desaparezca el servidor.

Algunas piezas de estas tipologías aparecen ya documentadas en el reinado anterior de Enrique III: en el castillo de Torremormojón consta la existencia de truenos disparados por

\footnotetext{
3 AGS. EMR, leg 1, fols. 109-121.

4 Juan Ximón ya consta en 1415 como maestro de hacer lombardas (Ribas, 1949: 114).

5 Martín Sánchez de Vedía junto a Juan Gutiérrez Ximón reparó en 1446 una lombarda en Valladolid.

6 AGS. EMR, leg 1, fols. 109-121.
} 
pólvora $^{7}$ ya en 1404, y parece que el uso de estas armas estaba muy generalizado en el primer cuarto del siglo XV, por cuanto una ciudad pequeña como Palencia contaba en 1422 con un buen arsenal compuesto de veinticinco truenos mayores y treinta menores, piezas que disparaban piedras labradas (Simón, 1895: 124) de ocho, seis y cuatro libras — en función del calibre del arma-, aunque también podían disparar flechas o virotones. O el arzobispo de Toledo que sólo en su castillo de Almonacid tenía en 1435 un 16 truenos entre grandes y medianos con sus respectivas cureñas, más otro trueno de mano y 222 bolaños de piedra (Benito, 1971: 82). Además este inventario nos documenta perfectamente cómo se disparaban los truenos, al emplear los artilleros «un fierro para poner lumbre a la polvora de los truenos».

Ya a finales del reinado de Juan II, se habían generalizado tres nuevos modelos de armas: la media lombarda, pieza de un calibre situado entre la lombarda y el trueno; la serpentina y, sobre todo, la culebrina. Respecto del uso de estas piezas, en abril de 1450 el mismo rey relata la rebelión de Pero Sarmiento en Toledo: «e se puso ya contra mí e contra mi pendón real con gente de armas, e fiso lanzar contra mí muchas piedras con bombardas, e truenos, e serpentinas, e culebrinas» (Benito, 1961: 206). Estas dos últimas, si nos basamos en su denominación, serían piezas muy similares con forma larga y estrecha, variando lógicamente el calibre y contando ambas con caña y servidor.

Centrándonos en la culebrina, debe recordarse que su uso y desarrollo irá aparejado con la adaptación de las fortalezas al empleo de las armas de fuego, incorporándose a las nuevas barreras - murallas más bajas que el castillo antiguo al que rodean- que dejan de ser para ballestería para convertirse en artilleras y en donde se emplazarán las nuevas culebrinas de barrera, modelo anteriormente citado y que, como todas las piezas del periodo, también emplea recámaras.

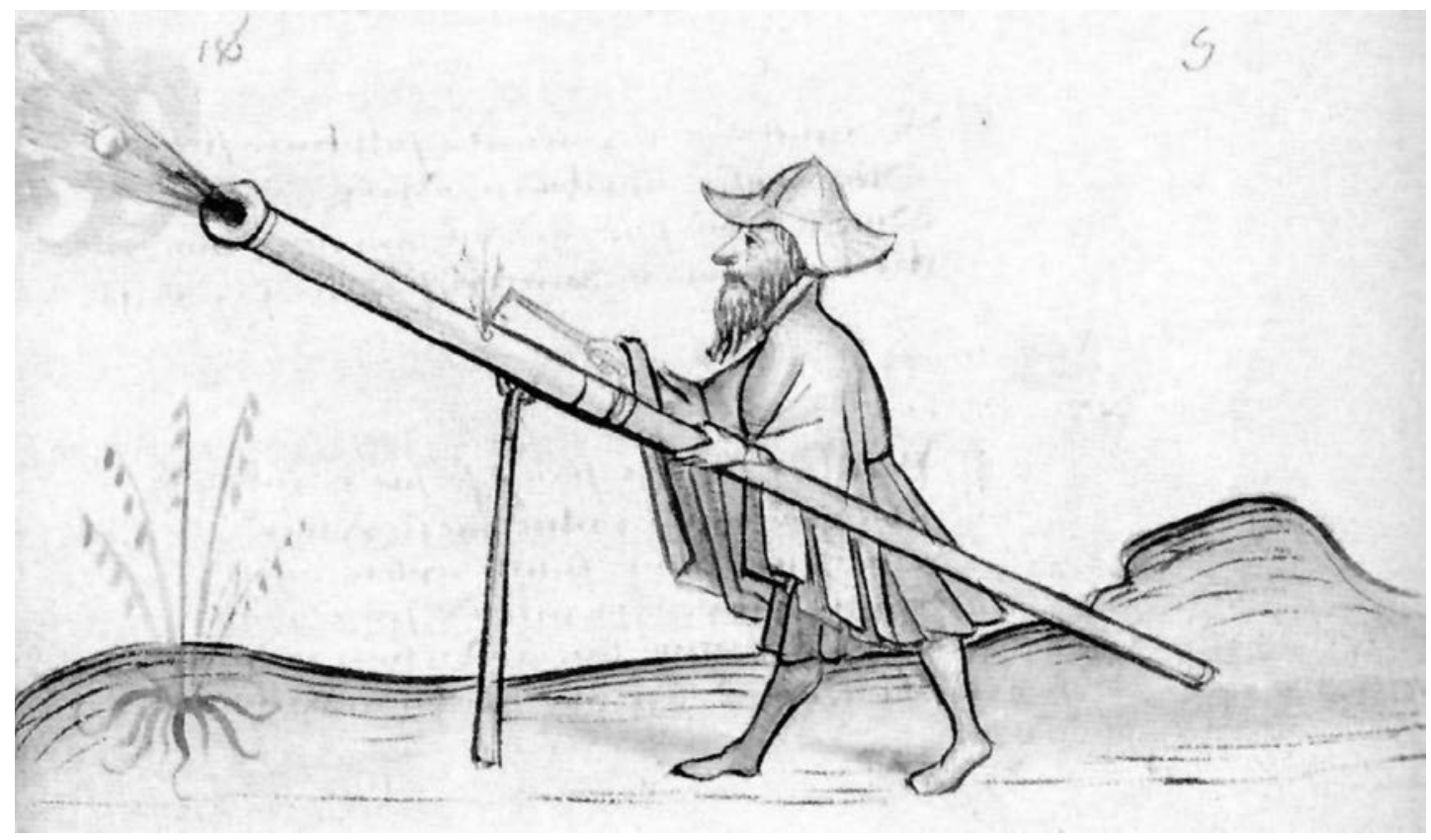

Figura 3. Peón con trueno de mano. Bellifortis.

7 RAH. CSC. S-66, fol. 19. 
En un primer momento, esta nueva arma disparaba flechas pero en seguida se adaptó también para disparar pelotas de plomo, ocupando un lugar entre los truenos y las armas tradiciones de cuerda como la ballesta. Son de destacar las culebrinas existentes en el alcázar de Curiel, donde se indica que son de $\langle\text { ferrametal }\rangle^{8}$ lo que nos puede llevar a interpretar que la caña y el servidor eran de hierro y bronce. Algo no extraño, por cuanto durante el reinado de Enrique IV se dieron casos del empleo de ambos metales en una misma pieza de artillería.

Contamos con cuatro inventarios señoriales (1451-1453) de los últimos años del reinado del Juan II de Castilla, en los que se recoge la existencia de varias piezas de hierro forjado, con caña y servidor, y en donde ya se documenta que disparan pelotas de plomo. El castillo de Matilla en $1451^{9}$ contaba con cinco truenos y tres culebrinas de hierro con tres servidores y sus respectivas cureñas, mientras que el de Castrojeriz disponía en 1452 de un trueno pequeño con servidor que tiraba «piedra de hasta 7 libras» (Morella y González, 1973). Alonso Pérez de Vivero disponía a su muerte en 1453 en sus palacios de Valladolid de un magnífico arsenal formado de once culebrinas con catorce servidores que disparan pelotas de plomo, dieciocho truenos con sus respectivos servidores y dos medias lombardas con cinco servidores ${ }^{10}$, mientras que los Zúñiga tenían en el alcázar de Curiel cuatro culebrinas con cureña en $1453^{11}$. Los especialistas en construir armas de fuego alcanzan un buen estatus durante el reinado de Juan II, es el caso del maestre Enrique contratado por el concejo de Murcia con el cargo de «maestro de fazer lombardas» (Martínez, 2010: 510) a cambio de un salario anual de $1.500 \mathrm{mrs}$., vivienda gratuita y exención de impuestos.

\section{ORGANIZACIÓN DE LA ARTILLERÍA REAL Y NOBILIARIA}

La organización del cuerpo real de artillería va ampliándose y mejorándose desde los tiempos de Enrique III a finales del siglo XIV, cuando al responsable de la artillería real Bernal Pérez se le denominaba «maestro de mis gombardas» ${ }^{12}$. En enero de 1463 se le llama maestro mayor de las mis artillerías, como consta en el nombramiento al comendador Sebastián con un salario de 20.000 maravedís anuales (De Castro y Cuadrado, 2004: 62-89). Este título es muy similar al empleado en la Corona de Aragón en 1457 de maestro mayor de las bombardas reales y de toda la artillería del Rey.

El comendador Sebastián disfrutó poco tiempo del cargo, por cuanto al año siguiente consta que mosén Juan de Peñafiel es «maestre mayor de artillerías de la guerra» (De Castro y Cuadrado, 2004: 62-89). Contamos con una nómina de octubre de 1464 en la que se relacionan bajo su mando a diez «lombarderos» ${ }^{13}$, de procedencia norteña a juzgar por sus apellidos: Santander, Arce, Galiciano y Agüero. El salario de Peñafiel es de 944 maravedís y el de sus lombarderos oscila entre 630 y 440 maravedís.

Este personaje será clave en la artillería del reinado de Enrique IV. Seguramente tuvo relación con el artillero judío Manuel de Peñafiel y está documentada su participación en la guerra contra Navarra, asistiendo al asedio de Viana de 1460. Creará la primera fundición autárquica de metal patrocinada por la Corona de Castilla y establecerá un importante centro de fabrica-

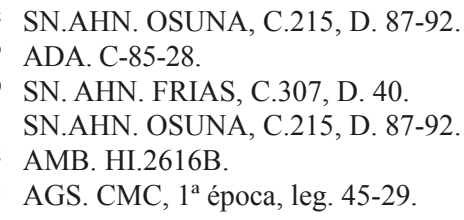


ción y depósito de pólvora en Roa en 1465. Este foco suministrará el detonante necesario para el asedio del castillo de Torrejón de Velasco.

La Corona castellana cuenta con más equipos de artilleros, que estarían estacionados en los castillos, como es el caso de Pascual Medrano, artillero del alcázar real de Segovia, quien cobraba en 1465 un salario de 5.000 maravedís de mantenimiento y 8.550 de ración. Otros equipos al servicio de la Corona son el capitaneado por el maestre Aleixandre, contratado por el capitán del ejército real Pedro Arias de Ávila para el asedio del castillo de Torrejón de Velasco junto a sus cinco oficiales de artillería, y el artillero Frutos, de clara ascendencia segoviana, quien también participa en el citado asedio.

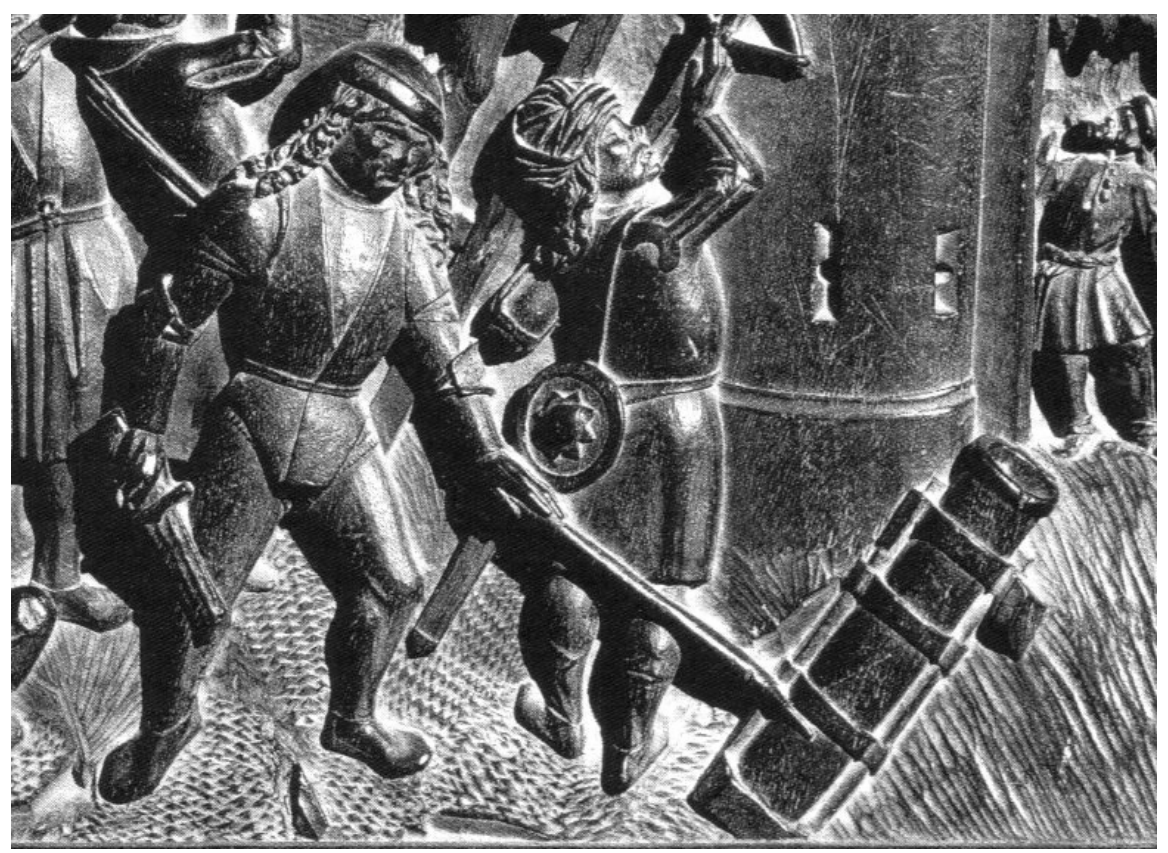

Figura 4. Artillero disparando una lombarda. Sillería del coro bajo de la Catedral de Toledo.

La alta nobleza también contaba con sus propios equipos artilleros, principalmente de lombarderos, que era el puesto más cualificado. Pedro Girón, hermano del duque de Villena, dispone de una organización similar a la de la Corona. Como responsable máximo tiene a Juan de Pasamer - con toda probabilidad el maestro artillero Juan de Pucemer ${ }^{14}$, que estaba al servicio de los Reyes Católicos en la zona de Jaén en 1479-, quien cuenta con un total de siete lombarderos y artilleros, entre los que destaca Pedro de San Jorge «artillero y maestro de hacer cureñas» (González, 1992). Las atenciones a su cuerpo de élite son máximas, ya que en su testamento de 1466 ordena que se paguen importantes cantidades a tres artilleros: «a Alfonso de Talavera, bombardero, $3.000 \mathrm{mrs}$.; a Sancho de Matute, bombardero, $4.000 \mathrm{mrs}$.; a Rodrigo de Matute, mi bombardero, $3.000 \mathrm{mrs}.\rangle^{15}$ Otros nobles, a título de ejemplo, que contaban en esos años con su propio equipo artillero son el valido del rey, Beltrán de la Cueva, quien en 1472 relaciona a los lombarderos Diego Núñez, Ferrero de Alegrete, Sancho de Aguero e Pedro

14 AGS. RGS, leg.147907,33.

15 RAH. CSC. M-104, fol. 11-17vo. 
de Ceballos ${ }^{16}$, o el duque de Medina Sidonia, que contaba en 1475 con los lombarderos maestre Alfonso y maestre Fernando, quienes además fabricaban pólvora y pelotas de plomo para los espingarderos (Gestoso, 1908: 233-234). Incluso el concejo de Palencia contaba en 1463 con un lombardero llamado Miguel Sánchez (Martínez, 1989: 166).

La guerra civil promovida por Isabel I contra su hermanastro y la posterior Guerra de Sucesión contra Juana de Castilla motivó la práctica aniquilación de la estructura artillera de la Corona castellana. Fernando el Católico hará llamar a su hermano Alonso, gran especialista en los temas de fortificación y artillería, quien viene acompañado de un pequeño equipo de especialistas. Entre ellos se encuentra micer Domingo Zacarías, a quien los reyes nombran en 1475 «maestro mayor de artilleria e pertrechos asi tiros de polvora como de otras qualesquier artillerias» ${ }^{17}$, con un sueldo de cincuenta maravedís de ración y 20.000 de quitación, con un salario anual de 38.000 maravedís por desempeñar un cargo que engloba tanto la artillería de fuego como la de torsión, como anteriormente hemos indicado. Parece que su servicio a los reyes finaliza tras el fin de la guerra contra Portugal, a no ser que el citado como mosén Domingo artillero que estaba fundiendo ribadoquines en Medina del Campo en 1482, y micer Domingo Zacarías sean la misma persona. En todo caso, en 1480 la dirección de la artillería real está a cargo del capitán Francisco Rejón ${ }^{18}$.

Centrándonos en los avances en la organización del ejército durante el reinado de Enrique IV, el monarca promoverá la creación de un nuevo cargo, denominado lombardero mayor, que posteriormente se llamará artillero mayor, una vez que la artillería de torsión deje de estar en activo. En 1476 este cargo lo ostentaba Juan Ximón ${ }^{19}$, miembro de la saga cántabra de los Ximón ya conocidos en los temas artilleros desde los primeros años del reinado de Juan II de Castilla. Su función sería de lugarteniente del maestre mayor, ayudando en el ordenamiento de un cuerpo de artillería cada vez más complejo.

Durante el reinado se va a crear también el cuerpo real de espingarderos. En el asedio al castillo de Torrejón de Velasco participan, al mando de un capitán, un total de treinta y tres espingarderos, entre los que se incluyen algunos de procedencia extranjera como Guillén de Flandes, Hanequín de Alemania o David de Bohemia ${ }^{20}$. Por su parte, la alta nobleza castellana también va a incorporar esta nueva fuerza armada: las referencias a espingardas y espingardones en los inventarios de las fortalezas son constantes y cada vez con un mayor número de piezas. En 1466 Pedro Girón contaba con una dotación de cinco espingarderos en su castillo de Carmona, mientras que en 1474 el duque de Alba disponía de un contingente de dieciocho espingarderos que cobraban 1.400 maravedís, y el duque de Béjar tenía en 1479 en la fortaleza de Arévalo una fuerza de diez espingarderos con un sueldo de 1.800 maravedís. Este avance en el empleo de espingarderos será una constante durante todo el siglo alcanzando la importante cifra de cien soldados armados con espingardas durante el asedio al castillo de Ponferrada de 1486. Del duque de Alba es conocido el magnífico trato que daba a su cuerpo de espingarderos, dotándoles en 1477 con una ración de despensa de tres arcillos de vino, dos panes, una libra y media de carne y pescado, cien maravedís de quitación al mes más otros cien maravedís al mes de vestuario ${ }^{21}$.

16 ADCA. Sig. 6, C-6, n 19.

7 AGS. RGS, leg. 147507,542.

8 AGS. CMC $1^{\mathrm{a}}$ época, leg. 180.

9 AGS. RGS, leg. 147605,330.

20 En las cuentas se incide en que son «espingarderos del dho señor rey».

21 ADA. Libro Maestro, fol. 599. Como bien ha apuntado Calderón (1996: 161) la ración de vino de los espingarderos era menor, tal vez por la naturaleza de su oficio. 


\section{CREACIÓN DE LA PRIMERA FUNDICIÓN AUTÁRQUICA DE BRONCE EN CASTILLA.}

A finales del reinado de Juan II, la Corona de Castilla y León toma una decisión sorprendente y única, que la diferencia de las otras coronas peninsulares: crear una fundición de bronce con la particularidad de poder controlar todos los pasos de fabricación de armas de artillería. La institución de un sistema totalmente autárquico, esto es controlar todo el proceso productivo incluyendo la extracción del mineral en minas situadas dentro del reino de Castilla y León, buscaba dejar de depender de la importación del cobre y del estaño — con todos los inconvenientes de precio y obtención de la materia prima que acarreaba traerla desde Flandes o de Europa oriental en pleno siglo XV-, problema compartido con Navarra y Aragón. No así el reino de Portugal que optó por adquirir la artillería de bronce directamente de las fundiciones establecidas en Flandes. En 1443 la Corona lusa compra la importante cantidad de 13 bombardas con 22 servidores o recámaras, 40 cañones con 79 servidores y 94 truenos con 168 servidores, en total son más de 400 elementos de bronce (Braancamp, 1908: 354).

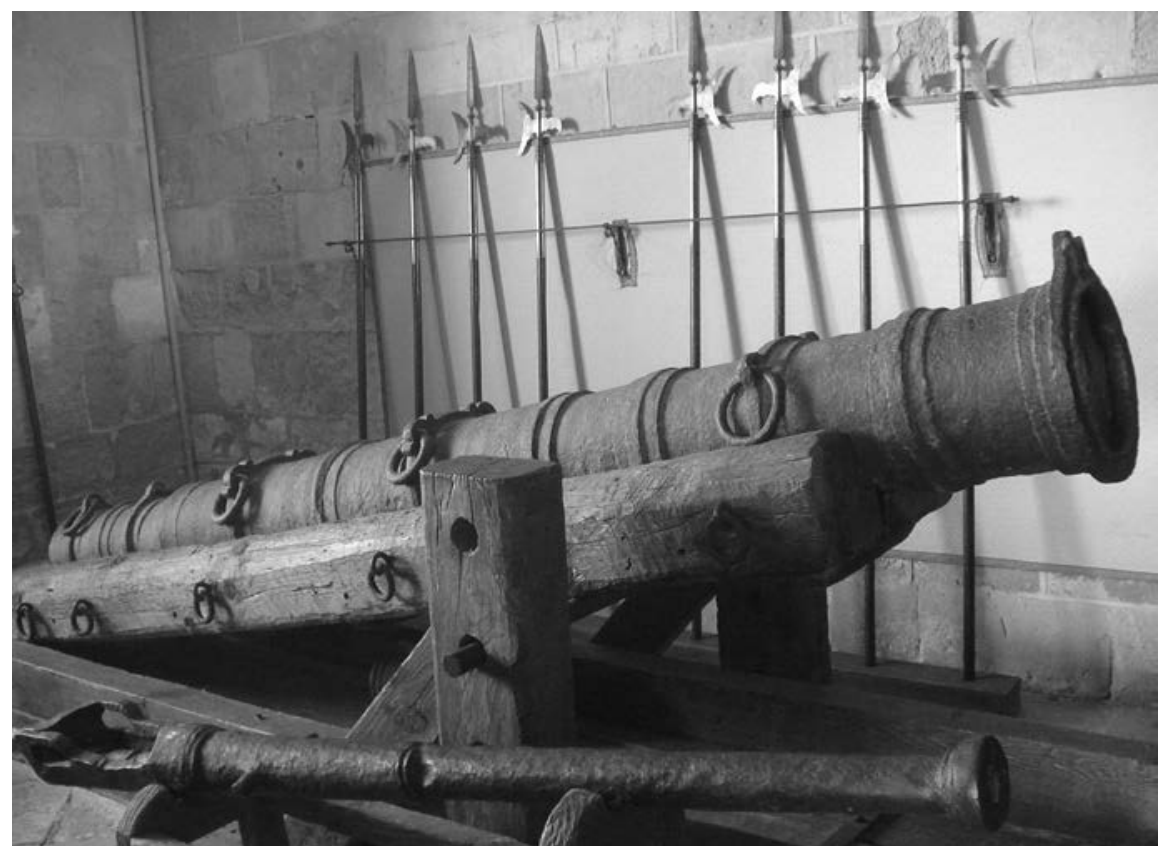

Figura 5. Lombarda de hierro del Alcázar de Segovia.

Como anteriormente hemos mencionado, el lugar elegido por la Corona de Castilla para el establecimiento de la fundición de bronce es en la sierra de la Demanda, zona con gran tradición de fabricación de forja: ya en el Libro de Montería de Alfonso XI se narra que con el hierro, carbón y agua que hay en su comarca «fue templada el espada de Durandarte que fue de Roldan» (Valverde, 2009: 257). La fundición se estableció en el pueblo de Barbadillo del Pez, emplazamiento que cuenta con minas de cobre y estaño ${ }^{22}$ y está relativamente cerca de Burgos, lo que facilitaría el acarreo de materiales para la construcción de la factoría. El encargado de la fundición fue el lombardero real Juan de Peñafiel, y los testigos de una probanza declaran que:

22 Documentadas desde 1583 (Canga, 1834: 314 y Auton, 1841: 7). 
...uno que se llamava mosen Juan que era artillero e lombardero del señor rey don Juan que viniera en aquella sazon el mosen Juan a labrar ciertas lombardas... mosen Juan de Roa que era lombardero del señor rey don Juan nro padre e viniera al lugar de Varbadillo del Pez a facer ciertas lombardas e otras artillerías... mosen Juan de Peñafiel que era lombardero del señor rey don Enrique nro hermano grand tiempo en el lugar de Varbadillo del Pez faciendo lombardas e otras artillerias para el señor don Enrique que estuvieren en el dho lugar por espacio de fasta ocho años. ${ }^{23}$

Descartamos que las piezas allí labradas fueran de hierro forjado por dos motivos: la cercanía de las herrerías vascas, con gran tradición en la fabricación con este tipo de material, y que próximo al lugar elegido para la fundición está la localidad de Barbadillo de Herreros, topónimo que ya consta desde 1044 (Martínez, 1987: 196), y que hubiera sido el lugar elegido en caso de una factoría de hierro forjado. La otra posibilidad es que se intentara crear artillería de hierro colado, si bien el no encontrar ninguna mención en los inventarios reales ni señoriales a este tipo de material y que todas las piezas documentadas sean de caña y servidor, nos hace descartar esta posibilidad.

En ocho años de trabajo, la fundición burgalesa debió producir diversas piezas para la Corona y es factible que una de ellas fuera la documentada en un inventario del castillo real del Pardo: «Una cebratana de fuslera en que tiene las armas reales del señor rey don Enrique en dos cabos $\rangle^{24}$. Por tanto, tenemos una pieza de bronce con las armas de Enrique IV, hecho que permite certificar el logro de crear una industria totalmente autárquica por el monarca, al uso de las existentes en Flandes. Sin embargo, esta dinámica se vio interrumpida drásticamente tras la guerra civil promovida por Isabel de Castilla contra su hermanastro.

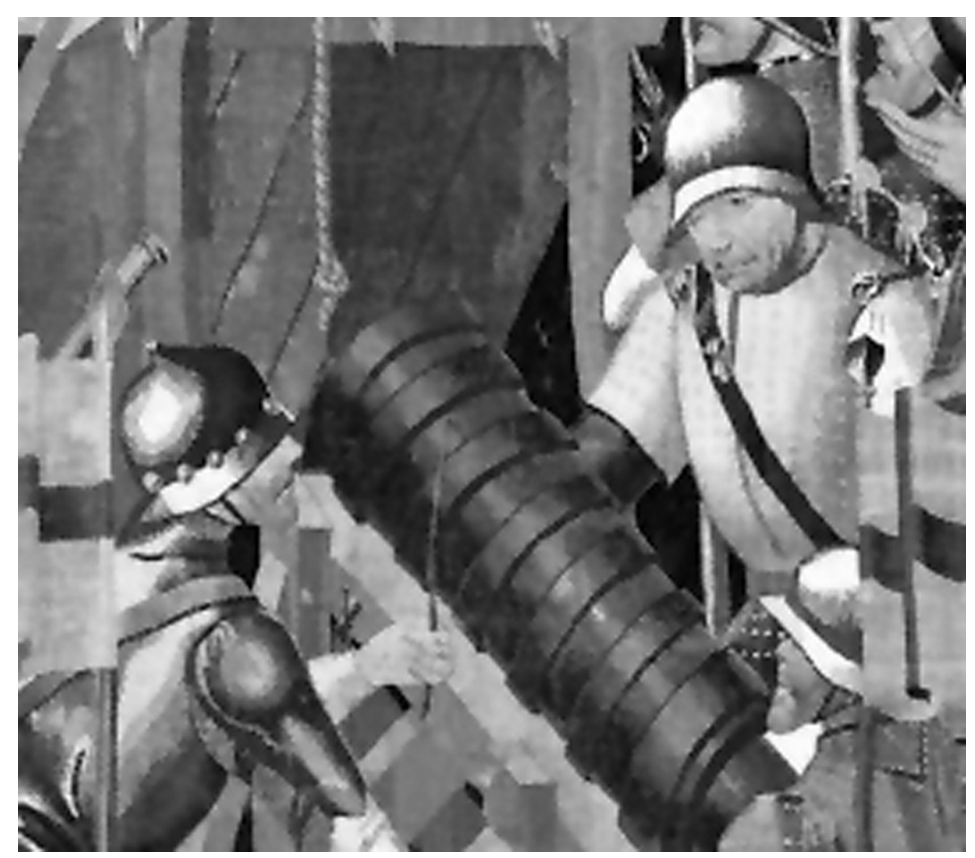

Figura 6. Artilleros disparando una lombarda de hierro.

Tapiz del cerco de Arcila. Colegiata de Pastrana.

\footnotetext{
23 RCHVA. Registro de Ejecutorias, C.86, D.1.

24 AGS. CS, $2^{\circ}$ serie, leg. 375.
} 


\section{LA ARTILLERÍA DE LA CORONA}

Para conocer los tipos y modelos de artillería empleados por la Corona de Castilla durante el reinado de Enrique IV contamos con las relaciones de los asedios de Viana, Torrejón de Velasco y Pagalajar y los inventarios de los alcázares de Segovia y Madrid y del castillo real de Soria.

En 1460 Enrique IV cerca la villa navarra de Viana «combatiéndola de lombardas, trabucos cortantes y otras diversas artillerías» (Martinena, 1994: 528), entre las que se encuentra una lombarda procedente de Soria y bajo la dirección de Juan de Peñafiel. Las lombardas reales fueron previamente reparadas en Logroño.

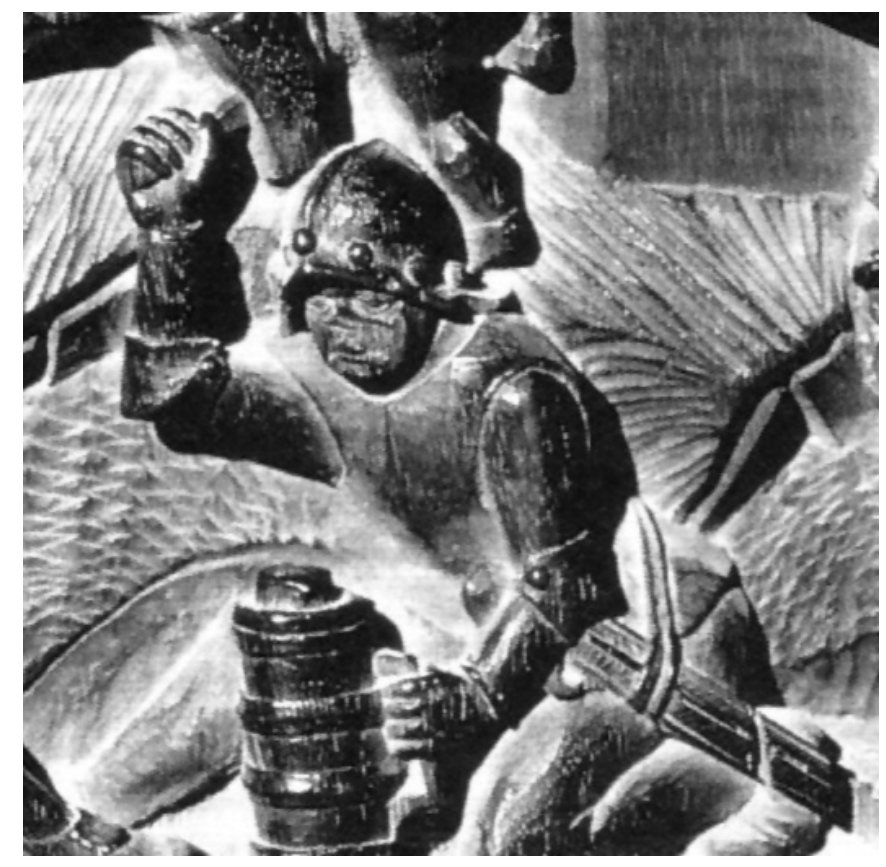

Figura 7. Artillero cargando una recámara.

Sillería del coro bajo de la Catedral de Toledo

En el asedio al castillo de Torrejón de Velasco en la primavera de 1465 destaca el empleo del cuartago del alcázar de Madrid, el uso de diversas lombardas, como la denominada mayor, más el uso de otras piezas medianas como truenos y cerbatanas, además de un importante contingente de espingarderos.

El asedio a la fortaleza de Pegalajar, en mayo de 1469, confirma que la Corona castellana contaba con un buen tren de artillería, lo que implica su correspondiente cuerpo de artilleros, en la Crónica de Lucas de Iranzo se narra que su Alteza llegó al «real e a las estancias do estaba la gente en el cerco juntamente dispararon tres o cuatro lombardas gruesas que estaban armadas e mas de otros cincuenta o sesenta tiros de pólvora y que no parecía sino que el cielo se rompía». La crónica reafirma el empleo de artillería gruesa y, sobre todo, de artillería mediana y ligera, al relacionarse nada menos que cincuenta a sesenta piezas. Podríamos pensar que el recuento incluyó piezas de mano como las espingardas, pero en cualquier caso la potencia de fuego sería bastante estimable. 


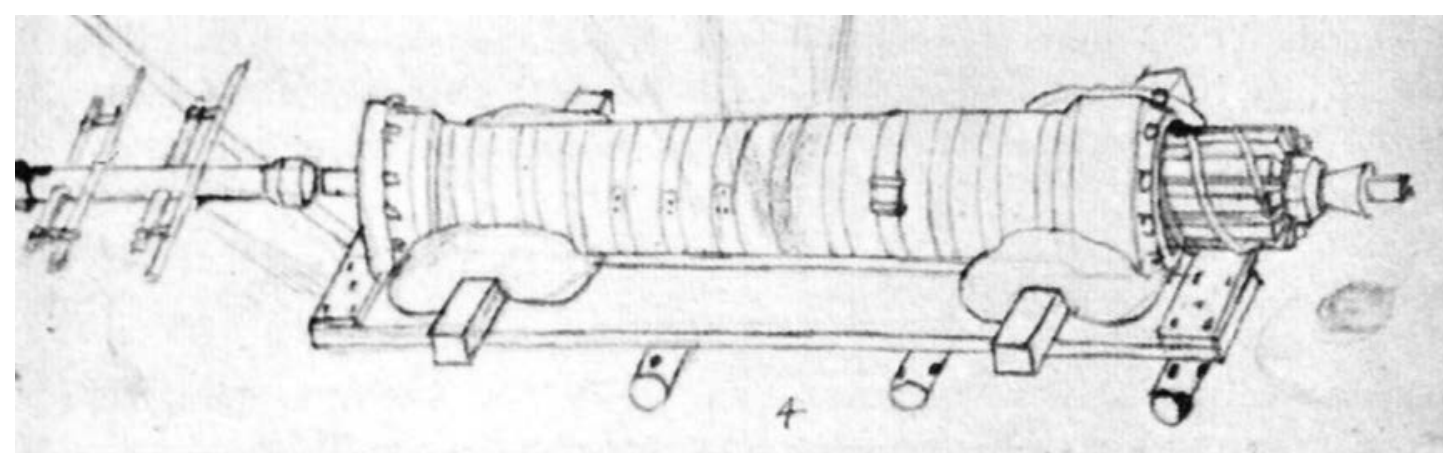

Figura 8. Fabricación del ánima de una lombarda. Leonardo da Vinci. Códice Atlántico.

Por tanto, durante los asedios la artillería real utilizará todo tipo de artillería gruesa, como cuartagos y lombardas; y más ligera, como truenos, cerbatanas y espingardas, y en cantidades bastante elevadas, como en el caso del asedio a la fortaleza jienense. Estas mismas piezas las encontramos documentadas en los inventarios de fortalezas reales. El alcázar de Segovia ${ }^{25}$ contaba con un buen arsenal formado por cortagos, lombardas, pasavolantes, y serpentinas. En 1465 Enrique IV manda tallar al cantero segoviano Pedro Polido la importante cifra de novecientos diez proyectiles de piedras, entre las que destacan cincuenta piedras grandes de peso de tres quintales cada una, para los cortagos, fechas e labradas por sus moldes a ochenta maravedís

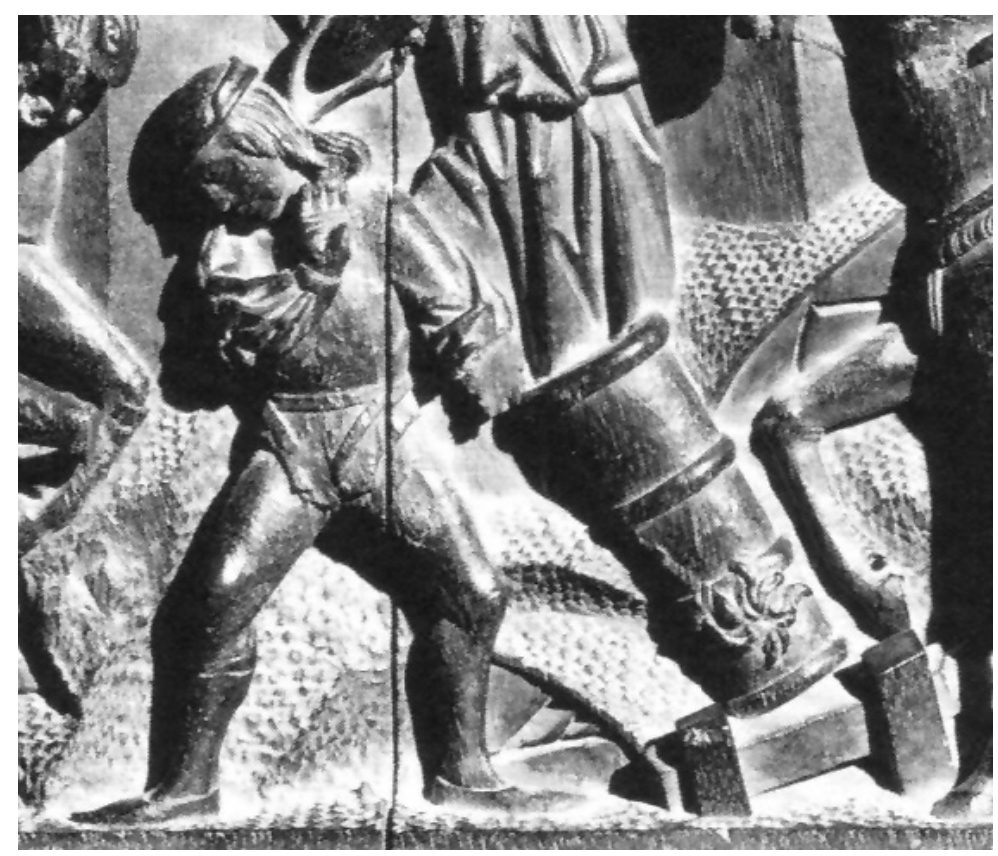

Figura 9. Artillero disparando un cortago. Sillería del coro bajo de la Catedral de Toledo.

25 AGS. CMC, 1 a época, leg. 84. 
por cada una, doscientas piedras para dos pasavolantes grandes y quinientas piedras para cuatro pasavolantes medianos. En noviembre de 1467 la artillería del alcázar segoviano estaba formada por tres cortagos con cureña, dos truenos con servidor y carretón, y una cerbatana, mientras que la artillería del Alcázar de Madrid se incrementaba en noviembre de $1468^{26}$ con un trueno, diez serpentinas, diecisiete espingardas de viratones y veintisiete espingardas de pelota. Por otra parte, en el castillo de Soria la Corona contaba con una lombarda, un pasavolante, cuatro serpentinas y un bollurto, todas ellas con servidores (Paz, 1978: 138).

Contamos con otros inventarios, realizados durante los primeros años del reinado de los Reyes Católicos, pero que muestran piezas del reinado anterior. El primero es de marzo de 1475, cuando se trasladan desde la Casa del Bosque de Valsaín al castillo de Medina del Campo un importante contingente formado por dos pasavolantes con cuatro servidores, dos truenos, diez cerbatanas con servidores y seis espingardas con cureñas, artillería toda ella de los arsenales de Enrique IV.

Posteriormente, Isabel y Fernando van a adquirir el arsenal reunido por Garci Bravo de Laguna entre 1476 y 1487, y depositado en el castillo de Atienza. Las piezas son ocho truenos, una media lombardeta, un ribadoquín de metal con su carretón, trece cerbatanas y veintidós espingardas ${ }^{27}$. Las cerbatanas y espingardas disparaban pelotas.

\section{EL TREN ARTILLERO REAL DEL MAESTRE JUAN DE PEÑAFIEL.}

En 1469, mosén Juan de Peñafiel, maestre mayor de artillerías de la guerra y vecino de Roa - villa del duque de Alburquerque - concierta durante la guerra civil entregar el tren artillero de Enrique IV de Castilla al príncipe Fernando de Aragón (De Castro y Cuadrado, 2004). Podemos pensar que la artillería real estaría en el castillo de Roa y por tanto bajo control de Beltrán de la Cueva, valido de Enrique IV, por lo que hay serias dudas de que Juan de Peñafiel pudiera llevar a buen fin este contrato al contar con la oposición del duque de Alburquerque. Lógicamente, siendo Juan de Peñafiel el responsable máximo de la artillería real, los cañones y artilleros que alquila pertenecen a la Corona de Enrique IV. Es de destacar que, al no estar adscritas estas piezas a un castillo real, podemos deducir que funcionaban como un verdadero tren artillero permanente, disponible para ser utilizado en diferentes zonas en conflicto sin tener que reunir piezas de otros castillos, evitando así la complejidad de su formación, pérdida de tiempo y desprotección del castillo de donde se sacasen.

El tren artillero de Enrique IV, del que era responsable Juan de Peñafiel, consta de un total de seis lombardas, con este desglose: dos lombardas que tiran piedra de dos quintales, con trompa (caña) de doce palmos de largo, más el servidor; dos lombardas que tiran piedra de un quintal, con trompa de once palmos de largo, más el servidor; dos lombardas que tiran piedra de quintal, con trompa de ocho palmos de largo, más el servidor; dos pasavolantes que tiran piedra de dieciocho a veinte libras y de largo de diez a once palmos, más el servidor; doce cerbatanas que disparan indistintamente pelotas o pasadores; seis carretones de hierro y en cada carretón tres tiros, lo que resultan dieciocho tiros que tiran pasadores de hierros de lanza, regatones de lanzas y cuadrillos gruesos para quebrar mantas y maderas chapadas. En total 38 piezas que sirven tanto para el asedio de un castillo como para una batalla en campo abierto.

Existen otros trenes artilleros como el que prestó el I duque de Alba a los Reyes Católicos para la toma del alcázar de Zamora en 1475. Las piezas fueron: «una lombarda gruesa con dos

\footnotetext{
26 AGS. CMC, 1 a época, leg. 84.

27 AGS. CSR, leg. 10, 39-42.
} 
servidores e otra lombarda menor que ella con sus servidores e otra lombarda mediana así mismo con sus servidores e otras dos lombardas menores que estas con sus servidores e dos ingenios uno grande e otro menor» ${ }^{28}$. Todas estas piezas se tasaron alcanzando la impresionante cifra de 480.000 maravedís: 150.000 por la lombarda mayor, 90.000 por la mediana, 20.000 por cada una de las menores y 75.000 cada uno de los ingenios.

\section{LAS PIEZAS DE ARTILLERÍA DEL REINADO}

Una curiosidad que sirve para ilustrar el valor otorgado a estas armas por sus dueños es que, al igual que en los reinados anteriores de Enrique III y Juan II, durante el reinado de Enrique IV de Castilla las piezas de artillería más importantes - lombardas - reciben nombre propio. Beltrán de la Cueva a sus lombardas del castillo de Alburquerque las llamaba Santa Lucía, Tomaçenisa y Bodoque. Por su parte, el marqués de Villena aludía a las lombardas del castillo de Chinchilla como Osoria, Chinchilla, Villena y Marquesa, y a un pasavolante como Pena. También el concejo de Sevilla disponía de la lombarda llamada doña Elvira, valorada en 150.000 maravedís.

Centrándonos en las tipologías, durante el reinado de Juan II las piezas utilizadas se limitaban a lombardas, medias lombardas, truenos, culebrinas y serpentinas. En tiempos de Enrique IV ya constan piezas grandes como el cortago, de tiro curvo, que irá sustituyendo a los ingenios del siglo XIV y los pasavolantes. Respecto a las piezas pequeñas, surgen las cerbatanas y espingardas. En un pasaje del año 1467, el cronista Alonso de Palencia comenta espingardas y cerbatanas, nombres nuevos impuestos por el vulgo, añadiendo que son armas ligeras. Podemos considerar que el trueno de mano acabó evolucionado a mediados del siglo $\mathrm{XV}$ en la espingarda. También durante el reinado de Enrique IV se documentan otras armas curiosas, como el órgano, y otras con vida efímera como el bollurto, que consta en el inventario del castillo de Soria.

Las piezas de bronce son abundantes y de todo tipo: lombarda, media lombarda, cerbatana, serpentina, ribadoquín, espingarda y truenos. Existen también piezas con servidores de metal y de hierro, como una serpentina de fuslera con su servidor de fuslera «e con otros dos servidores dellas de fierro» guardada en el castillo de Oropesa.

Ya durante la Guerra de Sucesión — primeros años del reinado de los Reyes Católicospodemos documentar piezas derivadas de otras ya existentes, como la media lombardeta, el medio pasavolante, el espingardón y los tronezuelos, apareciendo otros modelos como el ribadoquín de metal.

Otro elemento novedoso desarrollado durante el reinado de Enrique IV es la aparición del cartucho, que consta documentalmente en el asedio al castillo de Torrejón de Velasco de 1465, donde es empleado por las tropas de la Corona para servicio de las cerbatanas: «Por cinco manos de papel toledano para los cartuchos de las cebratanas 100 maravedís lo qual dio a Diego de Zalamea para gastar en las cebratanas $\rangle^{29}$. El papel toledano era de buena calidad, fuerte y grueso, por lo que servía para envolver de forma segura la pólvora. Es de destacar que ya durante el reinado de Enrique IV se generaliza el empleo del cartucho en las piezas de artillería, pero sólo en las de pequeño calibre, como las cerbatanas. Este caso no es aislado por cuanto en el inventario artillero del castillo de Porcuna en 1482 se citan «34 manos de papel toscano y 37

\footnotetext{
28 ADA. C-62-54.

29 AGS. CMC, 1 a época, leg. 45.
} 
manos de papel ceuty», obviamente tal cantidad de papel de la mejor calidad en un inventario de artillería sólo podía tener como uso la fabricación de cartuchos.

Respecto de la decoración de las armas artilleras, al igual que ocurre en otras zonas de Europa, las piezas castellanas tienen sus tiros de bronce decorados con representaciones de animales. Es de destacar una pieza que tenía en 1478 Álvaro de Zúñiga en su castillo de Béjar consistente en una cebratana de açofar que tiene una boca de sierpe.

Otro elemento interesante es la existencia en Castilla de piezas granadinas de bronce, adquiridas bien por compra, bien por conquista. Están documentados en el inventario del castillo de Piedrahita, propiedad del I duque de Alba, dos truenos pequeños de açofar moriscos. Lo interesante de este dato es que confirma que el reino de Granada también disponía de piezas de bronce y de fabricación propia. Además, por el tipo de pieza podemos pensar que la presencia de este tipo de armas se remonta a muy tempranas fechas del siglo XV.

Aparte de las tipologías y materiales, debemos citar algunas innovaciones tecnológicas significativas que se desarrollaron durante esta etapa histórica. Destacan los atacadores compuestos por un asta y un zoquete y empleados para comprimir tanto el cartucho al fogón del ánima del cañón, como la bala a este - para las serpentinas y otras piezas. Por su parte, los truenos tienen unos desarmadores, piezas que consisten en «unos fuelles y un casquete para desarmar los truenos».

Los datos de las cureñas aportan también novedades respecto a su diseño, al definirlos como «carretones e sus niveles de fierro» que disponen de un mástil o caballete donde colocar la barra de hierro y poder elevar el tiro, como la lombarda existente en el castillo de Villena que disponía de un caballete de madera con su apuntador de hierro e sus hebillas. Además, para sujetar la pieza a la cureña están las fajas que van hasta seis e incluso nueve en casos excepcionales, a lo que se añaden cinchos con hebillas, chavetas y cadenas como una «cureña gruesa con seis faxas e cinco cinchos e cuatro chavetas e cadenas en ellas e seis pernos que la atraviesan con su sortija a la coz» ${ }^{30}$. En algunos casos estos elementos estaban realizados en fuslera o metal.

Respecto de los proyectiles, tenemos moldes de piedra, metal e incluso de ladrillo «para fazer pelotas» de hierro, plomo o piedra, proceso en el que se utilizaban además herramientas especificas como «una escoda grande nueva para labrar piedras de lombardas $»^{31}$. El tipo de piedra de mejor calidad era la caliza procedente de Tordesillas. Otras piezas grandes, como los pasavolantes y serpentinas de mayor tamaño disparan pelotas de hierro o pellas. Por su parte, las piezas de pequeño calibre, como los truenos, serpentinas, culebrinas y espingardas pueden disparar pequeñas pelotas de plomo o viratones, pasadores o flechas emplumadas con plumas de hoja de lata.

Por último debemos hacer referencia a un tipo de pieza conocida como órgano, cuya presencia mencionamos anteriormente, al detallar el tren de artillería de Juan de Peñafiel. Es igualmente útil la referencia del Condestable en 1512 sobre las piezas guardadas en el castillo de Pedraza: «tiro de fuslera de çinco bocas que se llama desbaratavatallas» (Franco y Soler, 1994), que seguramente sea la misma pieza recogida en el inventario de 1430 que consistía en un trueno de fuslera de echar cinco piedras. También el duque de Béjar disponía de un modelo similar, consistente en «un carretón de fierro con dos truenos e sus aparejos metidos en un cajón $\rangle^{32}$. Piezas que demuestran que también la nobleza castellana contaba, ya desde el reinado de Juan II, con piezas específicas para el empleo en batalla a campo abierto.

\footnotetext{
30 SN.AHN. FRIAS, C.127, D.41 y C.100, D.11-13.

31 SN.AHN. FRIAS, C.127, D.41 y C.100, D.11-13.

32 SN.AHN. OSUNA, C.217, D.28-30.
} 


\section{LA ARTILLERÍA DE LA NOBLEZA}

Como hemos mencionado anteriormente, la artillería de fuego estaba plenamente desarrollada en el reino de Castilla en el primer cuarto del siglo XV no solo en el ámbito de la Corona, sino también de la nobleza. A modo de evidencia, un noble de segunda fila como Pedro Núñez de Herrera contaba a su muerte en 1430 en sus dos castillos de Pedraza y Torremormojón con un gran arsenal formado por piezas tanto de hierro como de fuslera. Las piezas gruesas eran tres lombardas de hierro, dos medias lombardas de hierro y una media lombarda de fuslera. Respecto de las piezas ligeras, el señor de Pedraza contaba con ciento diecinueve truenos de hierro y veintiún truenos de fuslera. Por último, las armas portátiles alcanzaban los ochenta y ocho truenos de vara de hierro, seguramente de los también denominados de mano. Además poseía dos piezas curiosas que demuestran que la Corona castellana contaba con artillería de campo: un «trueno de fuslera de echar cinco piedras» $\mathrm{y}$ «un trueno de tres armas de fuslera encajado ${ }^{33}$, armas que anticipan a las ya documentadas durante los reinados de Enrique IV y los Reyes Católicos. Un buen ejemplo lo tenemos en el asedio que formaliza en 1430 Juan II contra el castillo de Alburquerque y que a tenor de la Crónica los defensores dispararon contra el rey «en número de cincuenta truenos e lombardas» (Pérez de Guzmán, 1779: 291).

Contamos con bastantes inventarios de artillería de la nobleza castellana, lo que nos permite tener una visión muy completa del tipo y cantidad de armas que guardaban en sus arsenales. En marzo de 1461, Juan Ponce de León disponía en su castillo de $\operatorname{Arcos}^{34}$ de una lombarda con su cureña y tres truenos con su cureña, si bien uno de ellos se especifica «viejo de hierro», y disparaban bolaños de piedra. Por su parte, Beatriz Pacheco tenía en su castillo de Medellín (Cabrera, 1985: 545) en noviembre de 1463 una lombarda grande con su servidor, una serpentina de fuslera con dos servidores y su cureña y dos espingardas de hierro puestas en su carretón de hierro con dos servidores. En mayo de 1464, Alfonso de Sotomayor en sus castillos de Belalcázar, Puebla de Alcocer y Herrera (Cabrera, 1975: 38-39) disponía de cuatro lombardas de hierro, una lombarda de fuslera, tres medias lombardas de hierro, una media lombarda de fuslera, cuatro culebrinas, tres serpentinas de hierro, tres serpentinas de fuslera y tres espingardas. Pedro Girón tenía, en el castillo de Briones ${ }^{35}$ en marzo de 1465, cinco medias lombardas de hierro con servidor, nueve culebrinas de hierro que disparan pelotas y un trueno de mano de hierro. En abril de ese mismo año, en el castillo de Alburquerque, Beltrán de la Cueva contaba con tres «bombardas» ${ }^{36}$, y en agosto de 1468 un noble de escasos recursos como el mariscal Gómez de Benavides disponía en su castillo de Mota del Marqués de su propio parque artillero formado por dos truenos, un pasavolante y una espingarda de $a z o f a r^{37}$.

Los arsenales de la alta nobleza castellana continuaron ampliándose durante la guerra civil entre Enrique IV y su hermanastra Isabel de Castilla, y la posterior guerra de Sucesión. El duque de Villena disponía en el castillo de Chinchilla ${ }^{38}$ en 1477 — durante el primer ataque — de veinticuatro piezas, y en 1480, tras el fin de la contienda contra Portugal, había logrado reunir la impresionante cifra de cuarenta piezas, con este desglose: once lombardas, tres medias lombardas, cinco pasavolantes, tres medios pasavolantes, cuatro cerbatanas, un trueno, cuatro cuartagos, siete espingardas de llave, un espingardón y una espingarda de azofar.

\footnotetext{
33 AH. Nobleza. Baeza, C.114, D.37

34 SN. AHN. OSUNA, C.117, D.134.

SN.AHN. OSUNA, leg. 99, no 47-48.

ADCA. Sig. 6, C-6, no 19.

SN.AHN. FRIAS, C.1681, D.13.

SN.AHN. FRIAS, C.127, D.41 y C.100, D.11-13.
} 


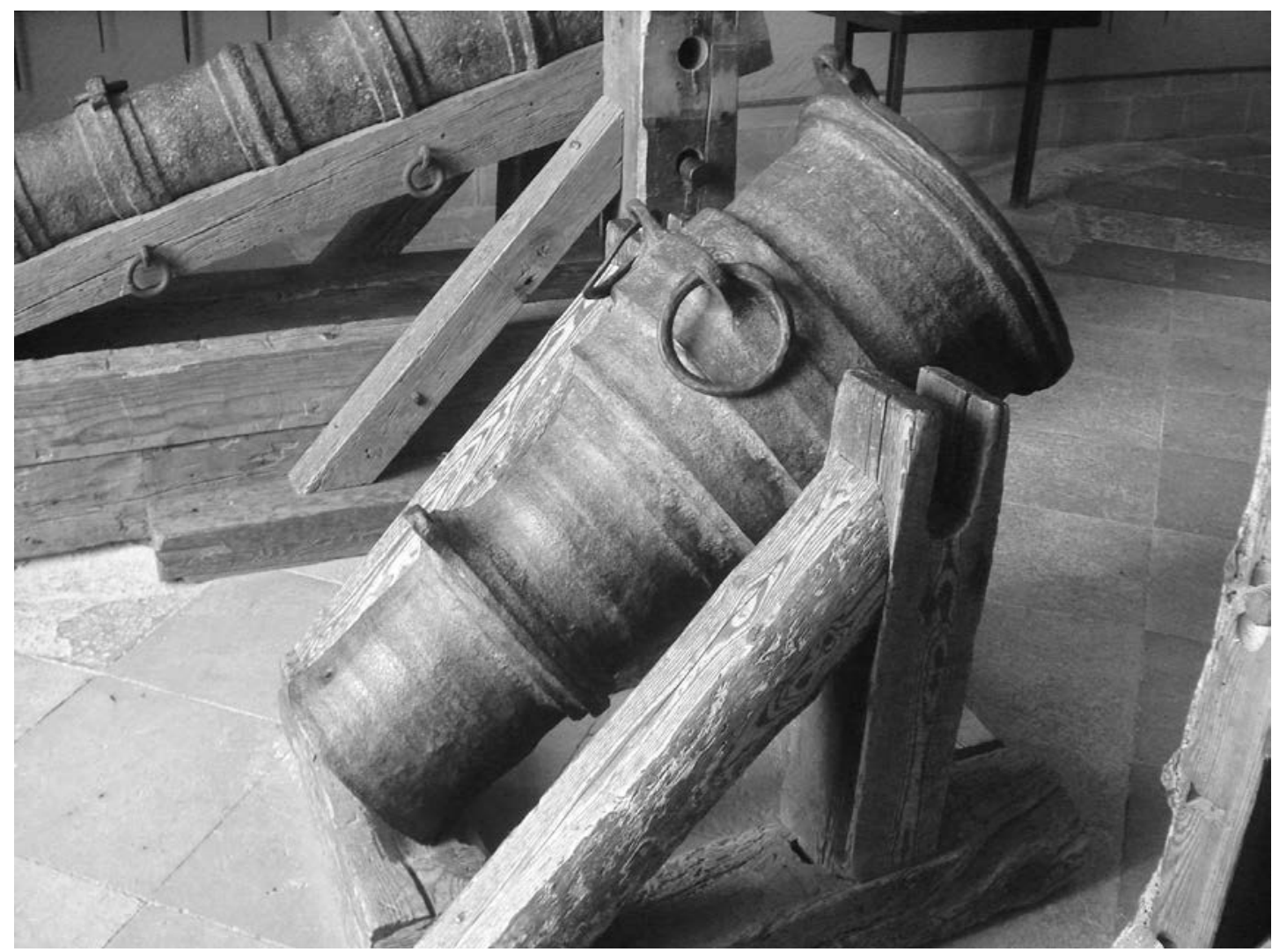

Figura 10. Cortago de hierro del Alcázar de Segovia.

Álvaro de Zúñiga contaba en diciembre de 1478 en su castillo de Béjar con las siguientes piezas: una lombarda, una cerbatana de azofar, ocho espingardas que tiran pelotas y seis truenos cortos de mano encabalgados. ${ }^{39}$ Por su parte, el duque de Alba disponía en su castillo de Piedrahita, en octubre de 1478, de un arsenal formado por una media lombarda, tres truenos grandes, seis truenos pequeños «encavalgados en sus curueñas, dos espingardas todas de fierro de tiros de pasadores de los que el duque mi señor fiso al tiempo de la guerra, dos truenos pequeños de acofar moriscos con sus curueñas de palo labrados de tornero, dos tronezuelos todos de fierro y cinco tronezuelos chiquitos de fierro $»^{40}$. En la que encontramos piezas curiosas como los tiros que hizo durante la Guerra de Sucesión, los dos truenos de bronce moriscos y el amplio abanico de truenos, tronezuelos y tronezuelos chiquitos. Mientras, que Alvar Pérez de Guzmán, a su muerte en 1483, contaba en sus castillos de Santa Olalla y Orgaz (Franco, 1988), con una lombarda de fuslera, tres medias lombardas de hierro, cuatro cebratanas, una serpentina, diecinueve espingardas y un espingardón.

Las órdenes militares también disponían de sus propios parques artilleros como la de $\mathrm{Ca}$ latrava que contaba en su fortaleza de Porcuna en 1482 de dos medias lombardetas, tres serpentinas, un pasavolante, dos culebrinas de barrera y doce espingardas, todas ellas con sus respectivos servidores y cureñas (Solano, 1987: 1621), mientras que la Orden de Santiago disponía en la Provincia de Castilla de 129 piezas de fuego, situadas principalmente en la zona

39 SN.AHN. OSUNA, C.217, D.28-30.

40 ADA. Libro maestro, fol. 1036-1040. 


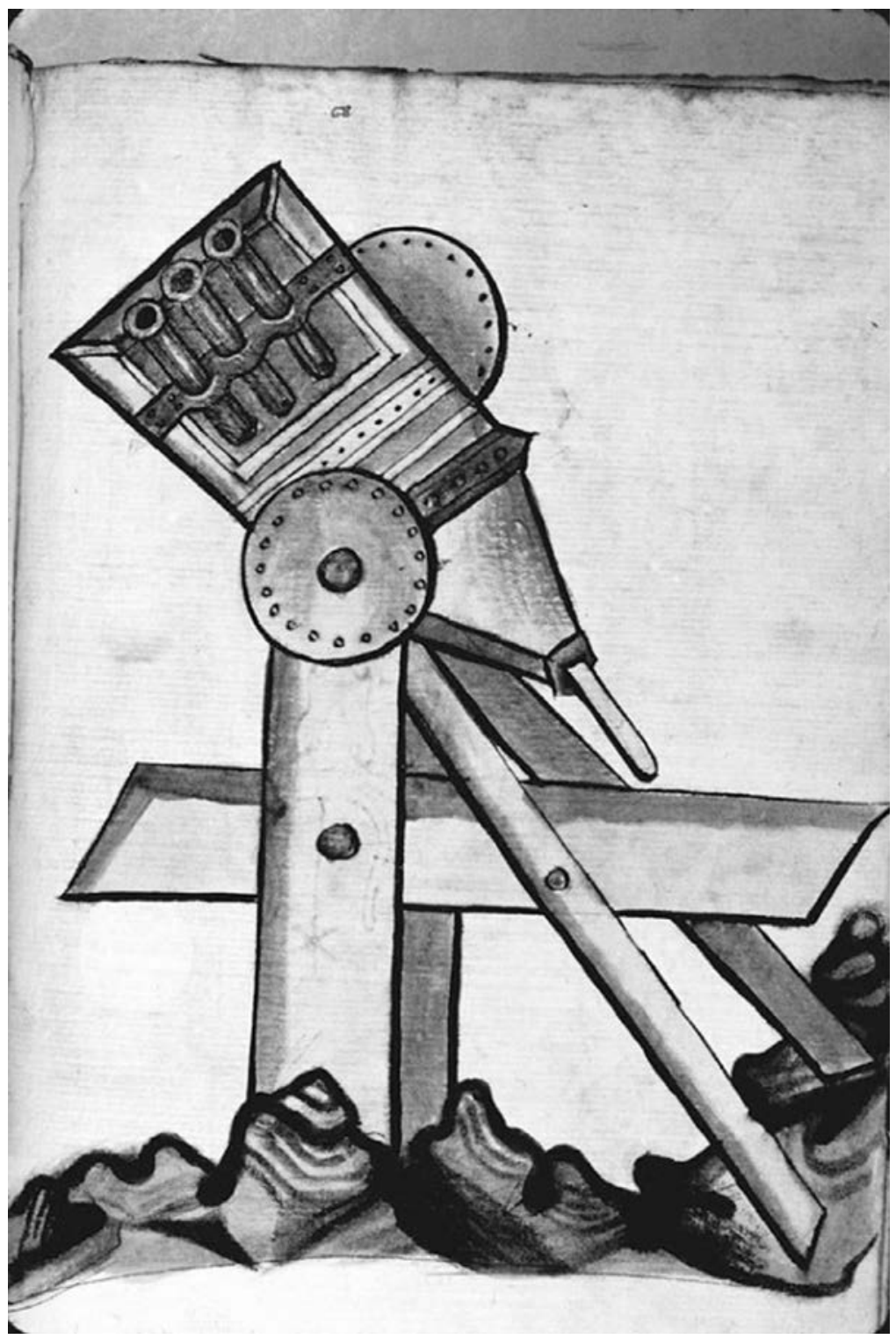

Figura 11. Un órgano con tres tiros. Bellifortis.

de Jaén frontera con el reino de Granada (Porras, 1997: 36). El arsenal de 1478 consistía en 2 lombardas, 8 medias lombardas, 39 truenos, 4 pasavolantes, 1 serpentina, 10 culebrinas, 5 cerbatanas, 52 espingardas, 2 espingardones y otros 6 tiros, artillería que se configuró previamente al reinado de los Reyes Católicos y al inicio de la guerra de Granada.

La hipótesis de que la posesión de armas artilleras estaba totalmente generalizada en la nobleza castellana del siglo XV encuentra su reafirmación en el caso de un pequeño noble, Diego Fernández de Quiñones, señor de Villanueva de Jamuz (León), quien al morir en 1484 (Alcedo, 1926: 164-169) contaba con un arsenal de una media lombarda, un pasavolante y catorce espingardas. 


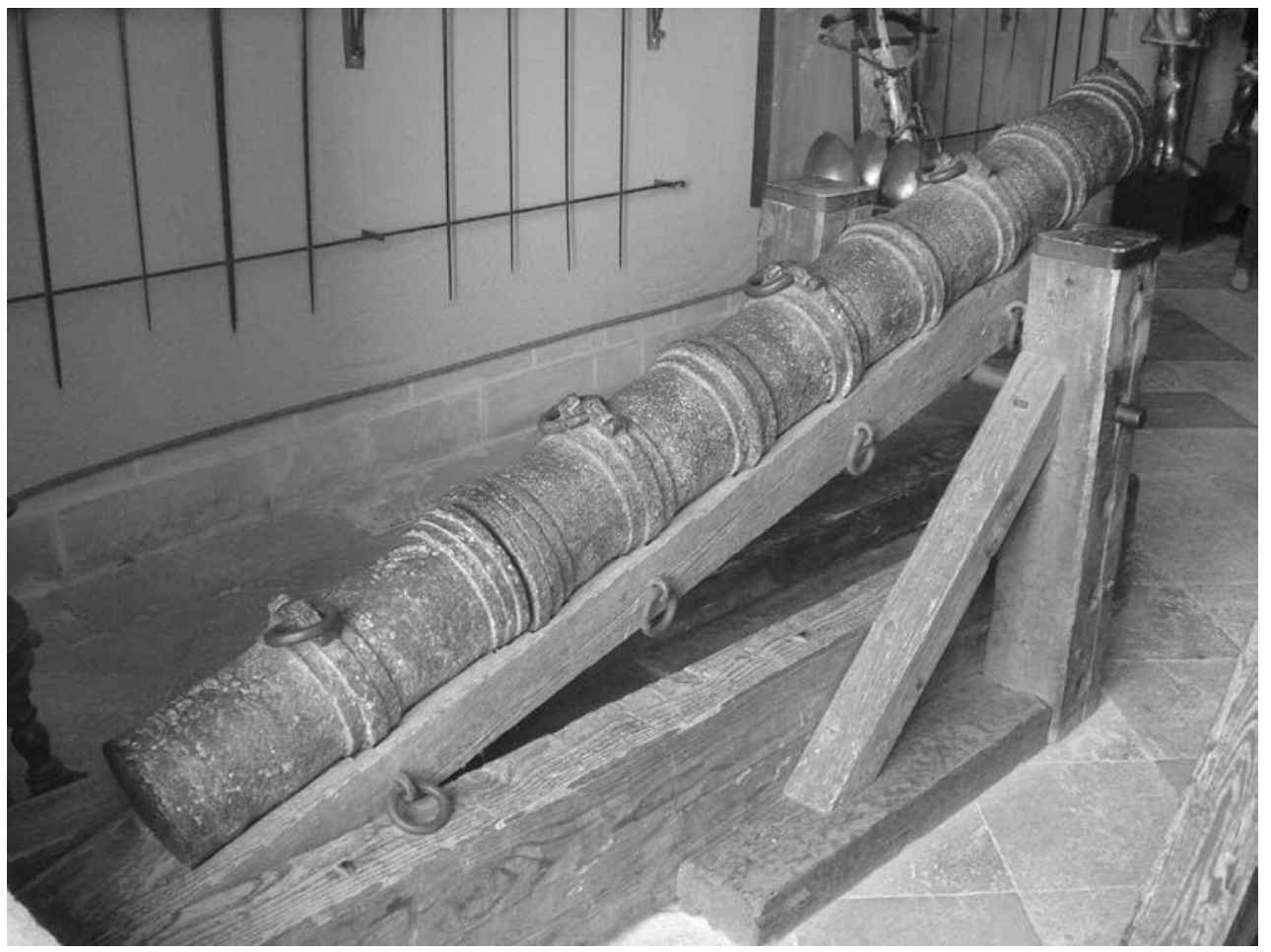

Figura 12. Caña y servidor del Alcázar de Segovia.

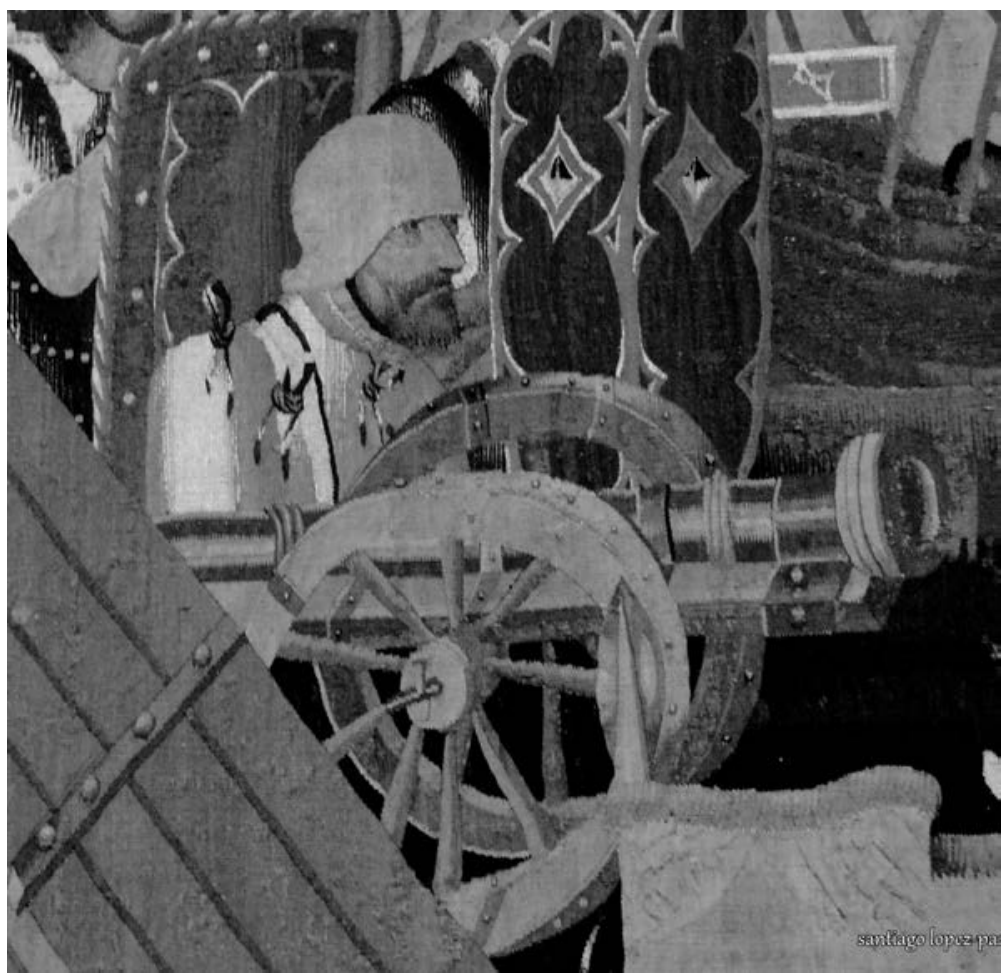

Figura 13. Pieza de metal. Tapiz del cerco de Arcila. Colegiata de Pastrana.

Gladius, XXXVIII (2018), pp. 99-124. ISSN: 0436-029X. https://doi.org/10.3989/gladius.2018.07 


\section{LOS INGENIOS}

Durante los reinados de Juan II y Enrique IV, las antiguas armas del siglo XIV continúan vigentes y se conjugan ambas artillerías la de torsión y la de pólvora. Tenemos el empleo de ingenios en las campañas contra el reino de Granada de 1407 y 1410 donde actúan los ingenieros Diego Alfonso y maestro Miguel y Juan Gutiérrez de Torres a quien se le titula como «maestro de las alas de la obra de la grua» o «maestro de las alas e escala» (Vilaplana, 1974). Durante la guerra contra Aragón y Navarra de 1429 los ingenios están almacenados en el castillo de Burgos y bajo la dirección de Rodrigo Alonso de Valbuena.

Los efectos de estos ingenios, trabucos y bastidas seguían siendo devastadores sobre las fortificaciones medievales. En 1461, durante el cerco del castillo de la Adrada, las tropas de Enrique IV emplazaron un ingenio que destruyó «las paredes como tejados e suelo» ${ }^{41}$, mientras que en el asedio al castillo de Torrejón de Velasco en 1465, la Corona atacó con el ingenio que estaba depositado en el alcázar de Toledo, al mando de «Navacerrada maestro mayor de faser engenos, y cuatro maestros sus compañeros» ${ }^{42}$ quienes fueron los encargados de transportarlo y armarlo ante la fortaleza asediada.

La nobleza castellana también seguía contando con esta arma entre sus arsenales. Beatriz Pacheco disponía en 1463 en su castillo de Medellín de «un engeño grande, con todo su aparejo, de madera de roble y un engeño menor», similar al de Bernardino Pérez Sarmiento en su castillo de Ribadavia. Pedro Girón utiliza en 1465 el yngenio de las Coronas, valorado en 550.000 maravedís y propiedad del concejo de Sevilla, para el asedio al alcázar de Carmona. El uso de estas armas está también documentado durante la Guerra de Sucesión, concretamente en el asedio al castillo de Chinchilla y en el asedio del alcázar de Zamora, donde el duque de Alba prestó dos ingenios valorados en 150.000

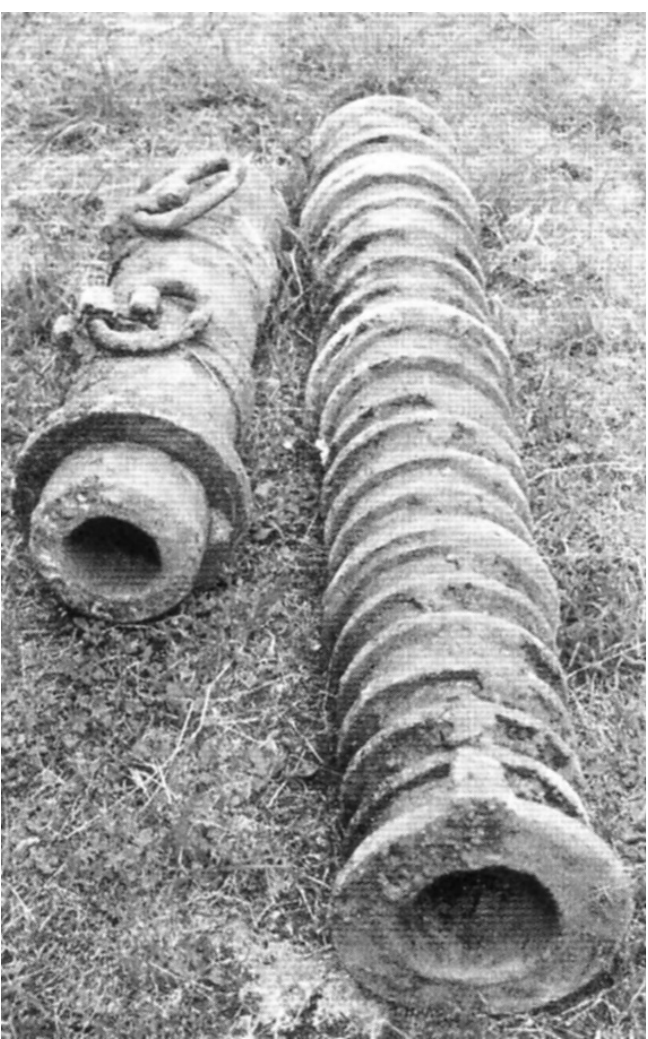

Figura 14. Lombarda encontrada en el castillo de Ponferrada. maravedís. La descripción del ingenio existente en el castillo de Chinchilla es bastante aclaratoria de las partes que lo componen: «dos exes de hierro e sus tornos e canal e aparejos e fonda e guindaleta e desarmador de cañamo e escalas». El empleo de estos artefactos no se daba sólo por parte del atacante, sino también del defensor, como ocurrió en el asedio al castillo de Chinchilla, donde aconteció uno de los últimos duelos de ingenios de la edad media.

\footnotetext{
41 AGS. CR-Obras y Bosques, leg. 97, fol. 185.

42 AGS. CMC, $1^{\text {a }}$ época, leg. 45.
} 


\section{LAS FUNDICIONES DE ARTILLERÍA}

Los inventarios de piezas de artillería guardadas en fortalezas señoriales durante el siglo $\mathrm{XV}$ nos muestran una gran cantidad de armas, tanto de bronce como de hierro. La fabricación de estas se ejecutó, entre otros ejemplos, desde tres factorías construidas por el duque de Alba, el conde de Ribadavia y el vizconde de Valduerna. Existían también otras de carácter privado, como las herrerías situadas principalmente en el País Vasco y las localizadas en ciudades reales como Murcia, si bien parece que en estos casos sólo se realizaba artillería de hierro de forja. De estas factorías particulares sabemos que, en 1480, tras la paz con Portugal, Isabel I de Castilla ordenó a los maestres armeros de Vizcaya, Guipúzcoa y Álava que entregasen las armas que tuvieren a Diego de Soria para proveer las fortalezas de Sicilia y la armada contra los turcos: «a qualesquier maestros de faser lombardas e cebratanas e otros tiros de polvora». Estos ejemplos son la continuidad de las factorías ya existentes en tiempos de Juan II como es el caso de la «lombarda que consigo habían traido de Cañete la qual Diego Hurtado avia mandado facer especialmente para combatir la cibdat» de Cuenca (De Mata, 1946).

Disponemos de los nombres de algunos de estos maestros, como Juancho y Perucho, contratados por García Álvarez de Toledo o el maestro Abrahim Alhajar, contratado por la ciudad de Murcia y citado en 1471 como «maestro mayor de fazer lombardas» ${ }^{43}$.

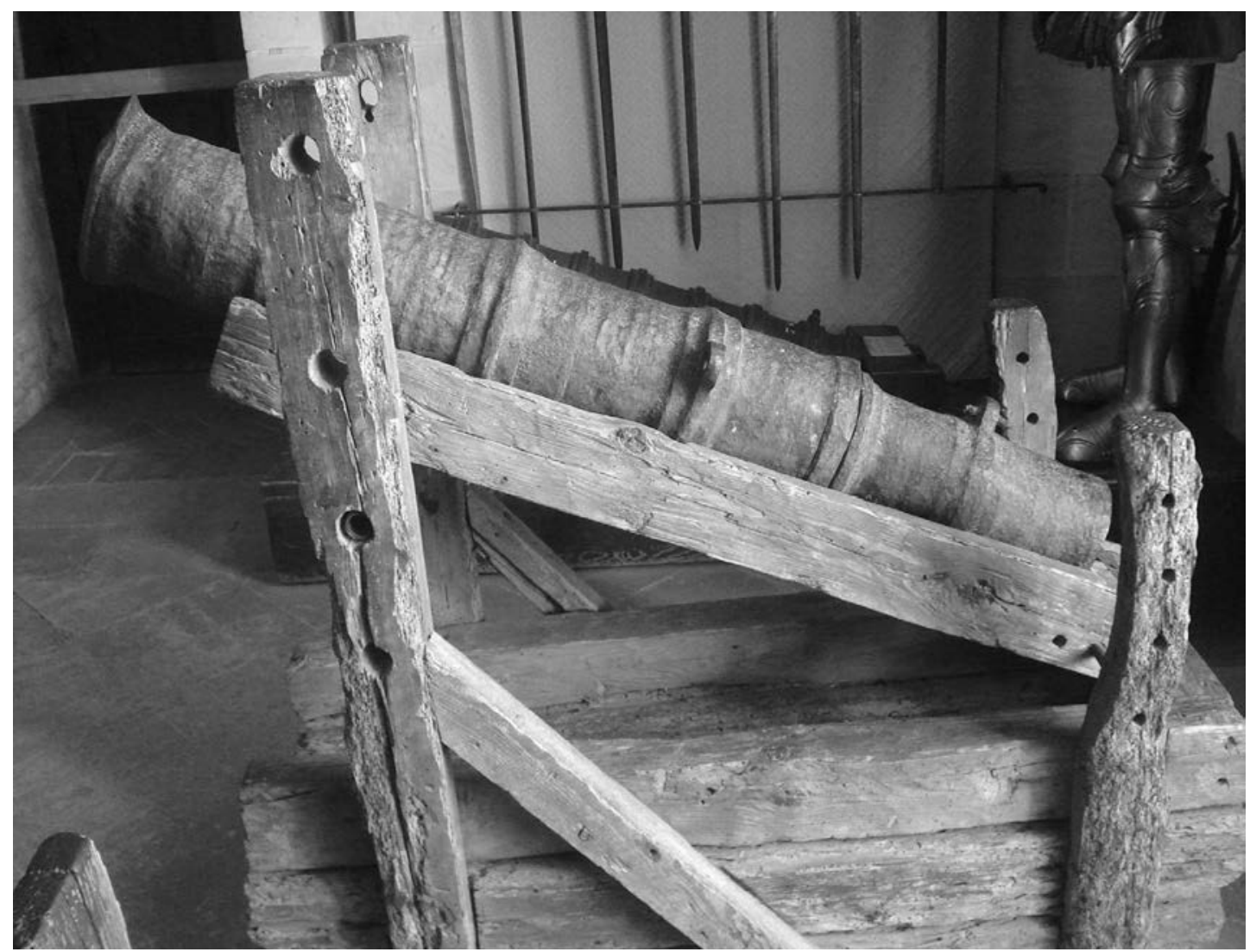

Figura 15. Caña y servidor de hierro del Alcázar de Segovia.

43 AMM. AC. 90, fol. 21 v. 
Debemos indicar que los lombarderos o artilleros, además de disparar las piezas, realizaban otras funciones como fabricar piezas, crear pelotería de hierro o plomo, hacer pólvora y montar cureñas. En noviembre de 1477, los lombarderos maestre Alonso y maestre Tomás Bárbara, además de disparar las dos lombardas grandes en el cerco de Utrera, fabricaron la pólvora necesaria ${ }^{44}$. Tenemos también otros casos curiosos, como el contrato suscrito por la Corona en noviembre de 1476 con Catalina Alfonso, maestra de hacer pólvora, con un salario de quince maravedís de ración y 3.000 de quitación (Ríos, 2015).

El conde de Rivadavia ordenó en 1479 la fabricación de seis cerbatanas de hierro en sus tierras de Galicia (Fernández, 2003), mientras que el vizconde Juan de Bazán compraba al conde de Lemos «grandes barras de fierro para faser lombardas» (Cooper, 1991: 988) en Palacios de Valduerna. Este dato nos lleva a deducir que muy seguramente Pedro Álvarez Osorio también hacía artillería de forja en sus señoríos gallegos y bercianos, ya que no solo tenía la suficiente materia prima, sino que incluso disponía de excedentes para vender.

Por su parte, el duque de Alba mandó crear en su señorío del Barco de Ávila entre los años 1476 y 1479 varias piezas, como dos medias lombardas de cuatro palmos de largo que tiran bala de una arroba de peso, dos cerbatanas - que fueron probadas en presencia del duque- $-\mathrm{y}$ dos servidores para dos lombardas ${ }^{45}$. Estas piezas no fueron las únicas que García Álvarez de Toledo ordenó fabricar, ya que en el inventario del castillo de Piedrahita se reseñan «dos espingardas todas de fierro de tiros de pasadores de los que el duque mi señor fiso al tiempo de la guerra», piezas que se utilizarían en la Guerra de Sucesión contra las tropas portuguesas. Las piezas debieron ser forjadas por Juancho y Perucho (Calderón, 2005), de quienes está documentada su incorporación al servicio del duque en 1474, trabajando durante un año con un sueldo de 30.000 maravedís y cuarenta fanegas de trigo. En 1475 se modifica la modalidad del sueldo, percibiendo 6.000 maravedís de tierra y cuarenta fanegas de trigo, cobrando aparte las piezas que realizasen para el duque. Existe un concierto posterior con el maestro Juan con un sueldo de 18.400 maravedís, repartido entre 14.400 de ración y 4.000 de quitación ${ }^{46}$.

Aprovechando la Guerra de Sucesión al trono castellano, el duque de Alba comprará varias piezas de artillería incautadas a los nobles partidarios de Juana de Castilla. Tras la conquista del castillo de Rabe adquiere en el verano de 1473 tres pasavolantes con seis servidores por 4.500 maravedís y posteriormente otros dos pasavolantes con cuatro servidores ${ }^{47}$ por tres mil maravedís. Según estas cuentas, el duque habría comprado en 1473 un total de cinco pasavolantes con diez servidores por un precio de 7.500 maravedís, a 1.500 por unidad.

Durante el reinado de los Reyes Católicos en 1486 se produce el gran asedio a un castillo señorial — de Ponferrada - por parte de la Corona ${ }^{48}$ (Cobos y De Castro, 2002: 124-125). Nos sirve para comparar los realizados durante los reinados previos de Juan II y Enrique IV y estudiar las fundiciones de cañones de metal realizadas en Benavente y Ponferrada.

La Corona va a solicitar la ayuda de la nobleza para que aporte las grandes piezas de asedio, las lombardas, en total cuatro: la del conde de Castrogeriz, llamada la Cocinera, con dos servidores; la del conde de Buendía, de Burgos y de María de Bazán. Aunque esta última también aportó artillería más ligera como cuatro pasavolantes, una cebratana y un ribadoquín. La parte más destacable es la artillería que se fundió ex profeso para el asedio. En total fueron veintitrés ribadoquines de metal: seis en la fundición que se estableció en Benavente y otros diecisiete en la misma Ponferrada. Para su ejecución se contrataron a los hermanos fundido-

\footnotetext{
44 AGS. RGS. leg. 147711,231.

45 ADA. Libro Maestro, fols. 422, 453 y 1095.

46 ADA. Libro Maestro, fols. 343 y 744.

47 ADA. Libro Maestro, fol. 37.

48 AGS. CMC, $1^{\text {a }}$ época, leg. 108
} 
res Pedro y Juan de Zamora y como ayudante especializado al campanero Andrés Sánchez. La proporción de bronce fue de 92,08 de cobre y 7,92 de estaño ${ }^{49}$. Se desarrollaron veinte procesos de fundición para obtener los diecisiete ribadoquines de Ponferrada y los maestros fundidores estuvieron asesorados por el artillero real Ramiro López, especialista tanto en fortificaciones como en fundiciones (De Castro, 2004).

En suma, vemos como a finales del siglo XV, al igual que en 1408, los campaneros tenían funciones de apoyo a los fundidores especializados y que el bronce era de una aleación ya perfectamente determinada y contrastada.

Además del cuerpo de artillería que participó en el asedio se contrataron diversos especialistas como lombarderos, tiradores de ribadoquines y polvoristas para el empleo de la artillería aportada por los nobles y entre los que se encuentran Pedro de las Cuevas, Mata Lion - francés-, González Vázquez, Juan Burgalés o Nicolao Balduque. Otros especialistas destacados en esta acción militar fueron García Álvarez, que hizo los moldes para las pelotas de los ribadoquines, y un equipo de siete canteros que labró los bolaños de piedra para las lombardas. En total, el tren reunido por los Reyes Católicos ascendió a la importante cifra de treinta y tres piezas de artillería, en un momento en que estaba en pleno desarrollo la guerra de Granada.

\section{CONCLUSIONES}

La evolución del arma de artillería durante este periodo es muy rápida. En un inventario de 1461 se habla de las piezas que son «viejo de hierro» ${ }^{50}$ ante el cada vez mayor predominio de las piezas fundidas en bronce, que como hemos visto debemos desterrar el tópico de su ejecución por campaneros y su fragilidad al tener supuestamente una gran proporción de estaño. Avance que continua cuando ya en otro inventario señorial de 1540 se hable de los cañones «del tiempo viejo» (De Castro y Mateo, 2016).

Desde principios del siglo XV, el papel que la artillería va a desempeñar en los ejércitos es asumido como imprescindible por los monarcas y nobles. En Castilla, Juan II, aprovechando el impulso dado por Enrique III, inicia el largo camino hacia la obtención de un cuerpo artillero propio, formado en sus fundiciones y dirigido por artilleros cada vez más cualificados. Su denostado hijo, Enrique IV, será quien consiga alcanzar la autonomía plena en el proceso de creación de armas, al fundar una fundición real de bronce en Barbadillo del Pez, bajo la dirección de Juan de Peñafiel.

El éxito de las empresas bélicas emprendidas por los reyes Isabel y Fernando (Cobos y De Castro, 2000) no pueden comprenderse sin los grandes avances que había alcanzado Castilla antes del comienzo de la guerra civil del reinado de Enrique IV. Realmente los Reyes Católicos no hacen sino recuperar esos conocimientos y continuar su desarrollo, proceso en el que la nobleza, ante el cada vez más complejo y caro proceso de fabricación y obtención de artillería, quedará relegada, como quedó demostrado durante la Guerra de las Comunidades de Castilla en la segunda década del siglo XVI.

49 Se compraron 60 quintales de cobre y 5 quintales y 16 libras de estaño para la fundición de los 17 ribadoquines de Ponferrada.

50 SN. AHN. OSUNA, C.117, D.134. 


\section{BIBLIOGRAFÍA}

Alcedo, Marqués de (1926): Un olvidado pleito del siglo XV: La herencia de Suero de Quiñones. Madrid, Blass S.A.

Arántegui, J. (1887): Apuntes históricos sobre la artillería española en los siglos XIV y XV. Madrid, Establecimiento Tipográfico de Fortanet.

Auton, N. (1841): El minero español. Madrid, Librería de Sojo.

Benito, E. (1961): Toledo en el siglo XV. Vida política. Madrid, Consejo Superior de Investigaciones Científicas.

Benito, E. (1971): «Visita de las villas y lugares del arzobispado de Toledo (1435)». Anales Toledanos, V: $82-83$.

Braancamp, A. (1908): «Maria Brandoa, a do Crisfal». Archivo Histórico Portuguez, VI: 293-442.

Cabrera, E. (1975): «La fortuna de una familia noble castellana, a través de un inventario de mediados del siglo XV». Historia, Instituciones y Documentos, 2: 9-42.

Cabrera, E. (1985): «Beatriz Pacheco y los orígenes del condado de Medellín». Anuario de Estudios Medievales, 15: 513-552.

Calderón, J. M. (1996): «La hacienda de los duques de Alba en el siglo XV: ingresos y gastos». Espacio, Tiempo y Forma, 9: 137-228.

Calderón, J. M. (2005): El ducado de Alba. La evolución histórica. El gobierno y la hacienda de un estado señorial (siglos XIV-XVI). Madrid, Dykinson.

Canga, J. (1834): Diccionario de Hacienda, vol. 2. Madrid, Imprenta de Don Marcelino Calero y Portocarrero.

Carrasco, A. (1887): «Apuntes para la historia de la fundición de artillería de bronce en España». Memorial de Artillería, serie III, tomo XV y XVI. Madrid, Imprenta del Cuerpo de Artillería.

Carrasco, A. (1889): «Apuntes de la historia de la fabricación de artillería y proyectiles de hierro». Memorial de Artillería, serie III, tomo XIX. Madrid, Imprenta del Cuerpo de Artillería.

Cobos, F. (coord.) (2004): La artillería de los Reyes Católicos. Salamanca, Junta de Castilla y León.

Cobos, F. y De Castro, J. J. (2000): «Artillería y poliorcética castellana en la estrategia de Fernando el Católico contra Francia». Gladius, 20: 251-268. https://doi.org/10.3989/gladius.2000.73

Cobos, F. y De Castro, J. J. (2002): Castillo de Ponferrada. León, Edilesa.

Cooper, E. (1991): Castillos señoriales en la Corona de Castilla, vol. II .Salamanca, Universidad de Salamanca.

De Castro, J. J. (2004): «Los ingenieros reales de los Reyes Católicos. Su nuevo sistema de fortificación», A. Valdés (coord.), Artillería y Fortificaciones en la Corona de Castilla durante el reinado de Isabel la Católica (1474-1504). Madrid, Ministerio de Defensa: 321-383.

De Castro, J. J. y Cuadrado, Á. (2004): «Los artilleros de los Reyes Católicos», F. Cobos (coord.), La artillería de los Reyes Católicos. Salamanca, Junta de Castilla y León: 62-89 y 138-147.

De Castro, J. J. y Mateo, J. (2016): «Ingenieros y artilleros en la Guerra de las Comunidades de Castilla», E. Martínez, J. Cantera y M. De Pazzis (eds.), La organización de los Ejércitos, Volumen I. Madrid, Cátedra Extraordinaria Complutense de Historia Militar: 538-593.

De Mata, J. (1946): Refundición de la Crónica del Halconero por el Obispo don Lope Barrientos. Madrid, Espasa-Calpe.

De Mata, J. (1982): Crónica de Juan II de Castilla. Madrid, Real Academia de la Historia.

Fernández, G. (2003): «Un ejemplo de hacienda nobiliaria gallega en el siglo XV: los ingresos y los gastos de don Bernardino Pérez Sarmiento, I Conde de Ribadavia, entre los años 1477-1478». Compostellanum, 48: 569-604.

Franco, A. (1988): «La Fortuna de Alvar Pérez de Guzmán. Alguacil Mayor de Sevilla y señor de Orgaz (1483)». Archivo Hispalense, 216: 37-67.

Franco, A. y Soler, Á. (1994): «Los arsenales de dos fortalezas castellanas: Inventarios de Torremormojón (1506) y Pedraza de la Sierra (1512)». Historia, Instituciones y Documentos, 21: 309-344.

Gestoso, J. (1899): Ensayo de un diccionario de los artifices que florecieron en esta ciudad de Sevilla desde el siglo XIII hasta el XVIII, Tomo I. Sevilla, La Andalucía Moderna.

Gestoso, J. (1908): Ensayo de un diccionario de los artifices que florecieron en Sevilla desde el siglo XIII al XVIIII inclusive, Tomo III. Sevilla, La Andalucía Moderna. 
González, M. (1992): «Cuaderno de notas de Gabriel Alfonso, escribano público de Carmona (146668)». Historia. Instituciones. Documentos, 19: 215-230.

González, S. (2013): Itinerario de don Fernando, regente de Castilla y rey de Aragón (1407-1416). Zaragoza, Institución Fernando el Católico.

López, F. J. (2011): Esculturas para la guerra. La creación y evolución de la artillería hasta el siglo XVIII. Madrid, Consejo Superior de Investigaciones Científicas.

Martinena, J. J. (1994): Castillos reales de Navarra. Siglos XIII-XVI. Pamplona, Gobierno de Navarra.

Martínez, G. (1987): Pueblos y alfoces burgaleses de la repoblación. Valladolid, Junta de Castilla y León.

Martínez, R. (1989): La arquitectura gótica en la ciudad de Palencia. Palencia, Diputación de Palencia.

Martínez, $\mathrm{M}^{\mathrm{a}}$. (2010): Cofradías de oficio y actividades suntuarias: el arte de la platería y sus orfebres en la Murcia medieval (ss. XIII-XV). En Homenaje al profesor Benito Eloy Ruano. Vol. II. Madrid. 493-519.

Morella, B. y González, J. (1973): Catálogo de los fondos documentales de la villa de Castrojeriz, tomados del Archivo general de los Duques de Medinaceli en Sevilla. Burgos, Exma. Diputación Provincial de Burgos.

Paz. J. (1978): Castillos y fortalezas del reino. Madrid, Ediciones Atlas.

Pérez de Guzmán, F. (1779): Crónica del señor rey don Juan Segundo. Valencia, Imprenta de Benito Monfort.

Porras, P. (1997): La orden de Santiago en el siglo XV. La provincia de Castilla. Jaén.

Ribas, M. (1949): «La casa de los Tiros». Altamira, VII: 111-130.

Ríos, R. (2015): «Catalina Alfonso: un maestre de fazer polvora durante el reinado de los Reyes Católicos». Gladius, 35: 105-116. https://doi.org/10.3989/gladius.2015.0006

Torres, J. (1980): «Murcia Medieval. Testimonio documental VI. La frontera, sus hombres, e instituciones». Murgetana, LVII. Murcia.

Salas, R. (1831): Memorial histórico de la artillería española. Madrid, Imprenta que fue de García.

Simón, F. (1895): «Palencia en el siglo XV. Su primer libro de Acuerdos municipales». Boletín de la Real Academia de la Historia, 26: 118-127.

Solano, E. (1987): «Una fortaleza de la Orden de Calatrava en Andalucía: Porcuna a finales de la Edad Media», J. Abellán (ed.), Homenaje al profesor Juan Torres Fontes, vol. 2. Murcia, Universidad de Murcia: 1619-1635.

Valdés, A. (coord.) (2004): Artillería y Fortificaciones en la Corona de Castilla durante el reinado de Isabel la Católica (1474-1504). Madrid, Ministerio de Defensa.

Valverde, J. (2009): Anotaciones al Libro de la Montería del Rey Alfonso XI. Salamanca, Universidad de Salamanca.

Vigón, J. (1947): Historia de la Artillería Española, tomo I, Madrid, Consejo Superior de Investigaciones Científicas.

Vilaplana, M. A. (1974): «Un ajuste de cuentas del Alcabalero Mayor de Sevilla Pedro Ortiz (1420)». Historia. Instituciones. Documentos, 1: 417-501.

Recibido: 06-06-2016

Aceptado: 11-10-2016 